\title{
درجة ممارسـة مدراء المدارس الحكومية في مديرية تربية بيت لحم ومديرية تربية يطا لمهارة إدارة الأزمات من وجهة نظر المعلمين
}

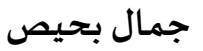 \\ أستاذ مشارك في الإدارة والتخطيط التربوي- جامعة القدس المفتوحة- فلسطين \\ jbheis@qou.edu \\ إسماعيل محمد الأفندي \\ محاضر في الإدارة والتخطيط التربوي- جامعة القدس المفتوحة- فلسطين \\ iafandi@qou.edu
}

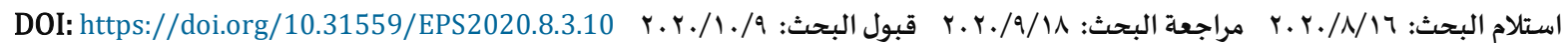

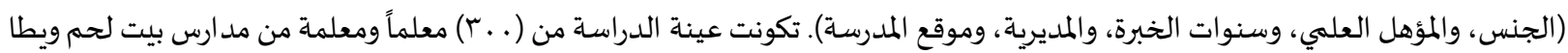

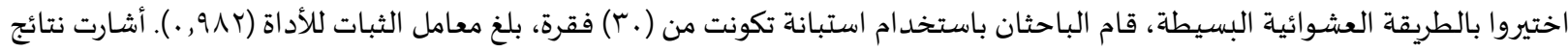

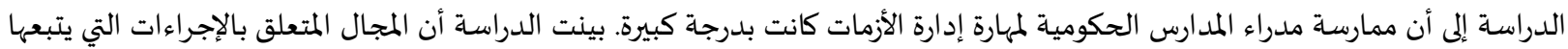

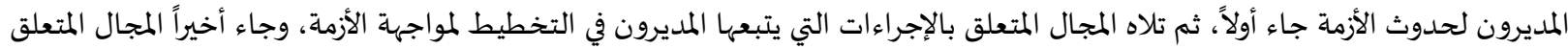

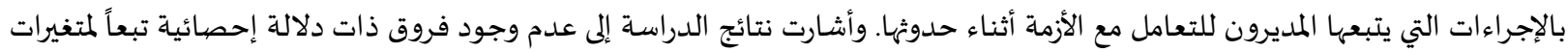
(المؤهل العلمي وعدد سنوات الخبرة وموقع المدرسة). وأظهرت عدم وجود فروق ذات دات دلالة إحصائية تبعاً لمتفير الجنس في المجال المال الأول، بينما

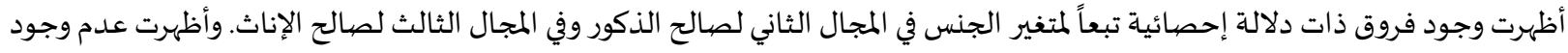
فروق ذات دلالة إحصائية تبعاً لمتغير المديرية في المجال الأول. بينما أظهرت وجود فروق ذات ذات دلالة إحصائية تبعاً لمتغير المديرية في المجال الثاني

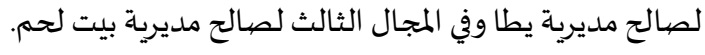
الكلمات المفتاحية: مهارة إدارة الأزمات؛ وجهة نظر المعلمين؛ مدارس حكومياة.

تولي الدول المتقدمة والنامية على السواء اهتماماً كبيراً بالتربية، وذلك استناداً للدور الفاعل الذي تقوم به في تقدم المجتمعات ورقهها، لهذا أصبحت التربية من أهم الوسائل التي تستعين بها الدول كافة في حل قضاياها الاجتماعية والاقتصادية وتحقيق الرفاهية والتقدم، وذلك باعتبارها إحدى الأدوات الرئيسة في إعداد القوى البشرية المدربة، والقادرة على صنع التقدم وقيادته، الأمر الذي يستوجب توفير العديد من المتطلبات، منها

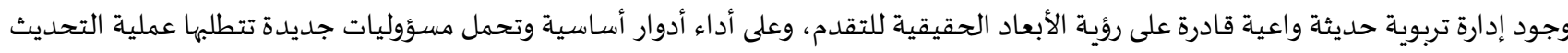

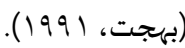

والعملية الإدارية أمر تحتاجه جميع التنظيمات، فما يميز المجتمعات المتقدمة على المجتمعات النامية هو حسن الإدارة وكفاءتها والقدرة على استغلال الموارد البشرية والمادية لتحقيق الأهداف المرجوة بأعلى درجة من الكفاءة، وقد أحدثت التطورات التكنولوجية وما زالت تحدث تغيرات كثيرة 
في تشكيل الإدارة، وأصبحت نظم الإدارة تجد نفسها مرغمة على تطوير أساليها ومناهجها، لمواجهة المواقف المتجددة التي تحمل في طياتها مخاطر لا حدود لها.

وقد بدأ الفكر الإداري مع منتصف الستينيات يحدثنا عن الأزمات، ومفهومها وخصائصها، وأنواعها، وأسباب نشوئها، والمشاعر المصاحبة لها،

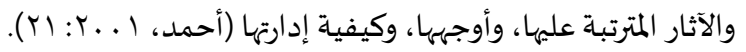

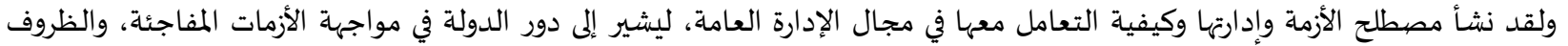

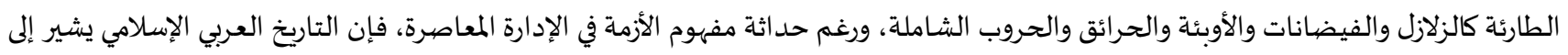

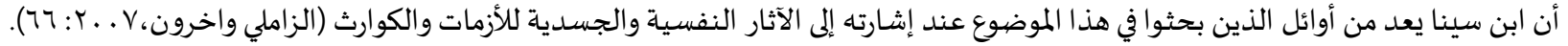

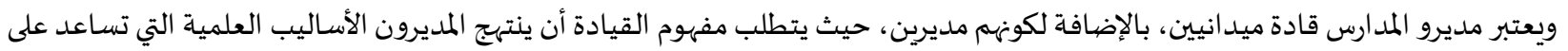

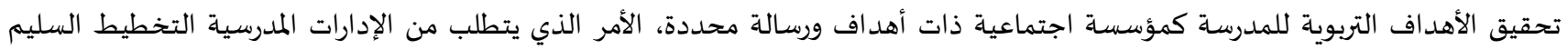

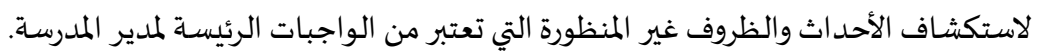

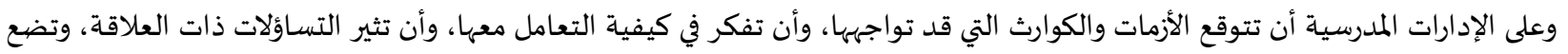
حلولاً ناجحة من خلال الخطط الموقفية.(أبو فارة، ج . . ب).

مشكلة الدراسـة: من خلال عمل الباحثان في المجال الإداري التربوي، وملاحظتهما للأزمات التي تواجه مدراء المدارس، وتباين أدوار مديري المدارس الحكومية في

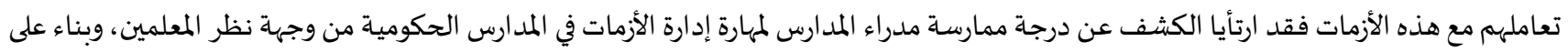

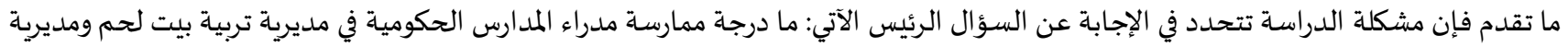

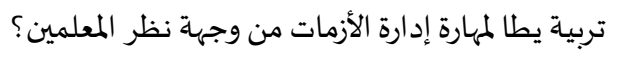
وقد انبثق عن السؤال الرئيس الأسسئلة الفرعية الآتية:

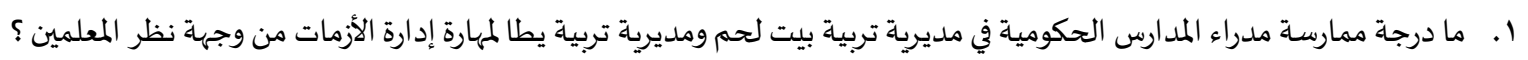

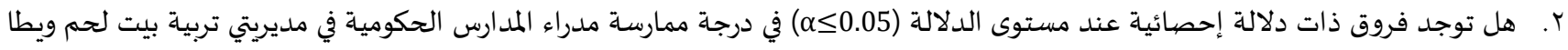

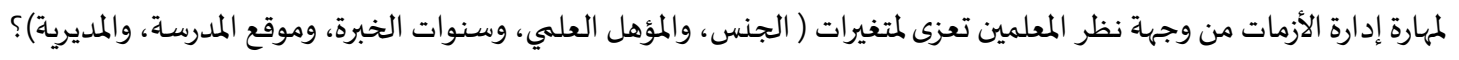

فرضيات الدراسة:

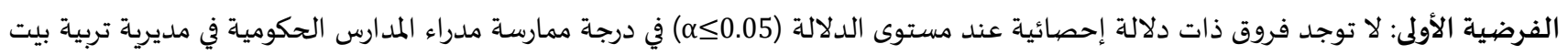

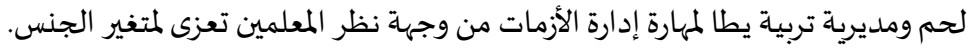

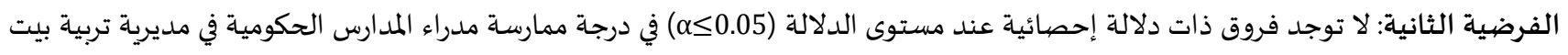

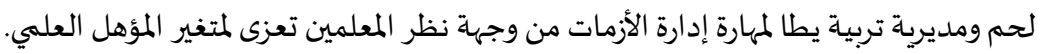

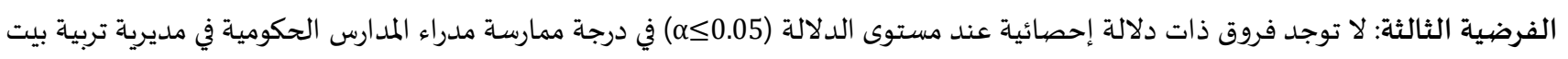

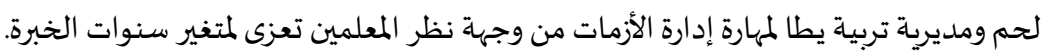

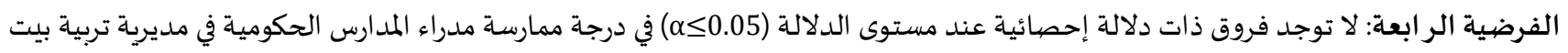

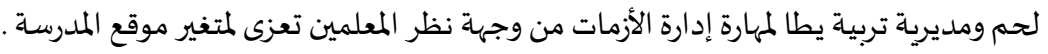

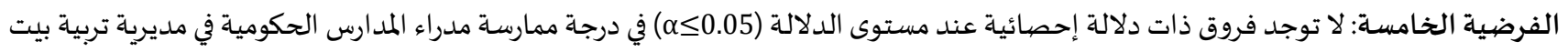

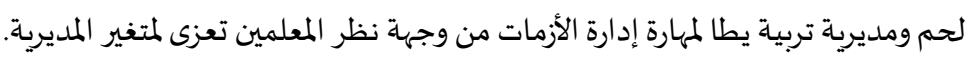
أهداف الدراسة: هدفت الدراسة إلى: ا. التعرف على درجة ممارسة مدراء المدارس الحكومية في مديرية تربية بيت لحم ومديرية تربية يطا لمهارة إدارة الأزمات من وجهة نظر المعلمين . ويتفرع عن الهدف الرئيس أهداف فرعية أهمها: ا. الت التعرف إلى درجة ممارسة مديري المدارس الحكومية لمهارة إدارة الأزمات من وجهاة نظر المعلمين.

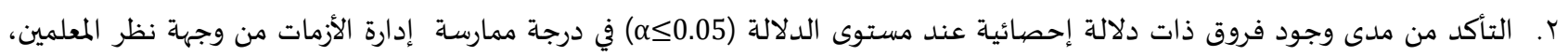
والكشف عن أثر كل من متغيرات ( الجنس، والمؤهل العلمي، وسنوات الخبرة، وموقع المدرسة، والمديرية). 
أهمية الدراسـة:

هناك حاجة متزايدة لدراسة المراكز والأدوار القيادية، ومتطلبات الأداء الناجح والمعوقات التي تعرقل هذا الأداء، للتعرف على نواحي القوة من أجل دعمها، وعلى نواحي الضعف من أجل اصلاحها وتداركها وتلافيها في أي تخطيط مستقبلي، (رمزي، و 99 ( ).

وتظهر أهمية الدراسة الحالية فيما يلي:ا. تعتبر من الدراسات الأولى التي ستكشف عن أساليب إدارة الأزمات في مديرية تربية بيت لحمرومديرية تربية يطا ،على حد علم الباحثين.

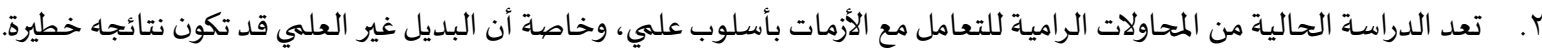

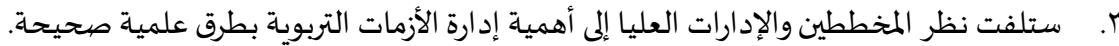
ع. سيستفيد من هذه الدراسة كل من : مدراء المدارس بشكل عام

القائمين على متابعة مديري المدارس في وزارة التربية والتعليم العالي.

الباحثين في مجال الادارة التربوية.

حدود الدراسـة:

الحدود البشرية: معلمي ومعلمات المدارس التابعة لمديرية التربية والتعليم/بيت لحم ومديرية التربية والتعليم / يطا. الحدود المكانية: جميع المدارس الحكومية التابعة لمديرية التربية والتعليم / بيت لحمى ومديرية التربية والتعليم/ يطا.

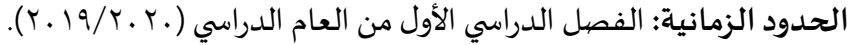
الحدود الموضوعية: تشمل حدود الدراسة الموضوعية درجة ممارسة مديري المدارس الحكومية لمهانية المارة إدارة الأزمات من وجهة نظر المعلمين، وتقديم المقترحات التي تساهم في التغلب عليها .

مصطلحات الدراسة:

مدير المدرسة: هو المسؤول المباشر أمام المنطقة التعليمية عن إدارة شؤون المدرسة الفنية والإدارية.(الهنائي، ب . .؟ . ـ ().

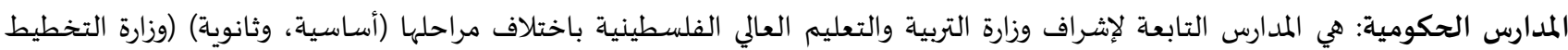
والتعاون الدولي، (199V). الأزمة: يعرفها حجي بأها: نقطة تحول في سلسلة من الأحداث المتتابع تسبب درجة عالية من التوتر، وتقود إلى نتائج غالباً ما تكون غير مرغوبة، وبخاصة

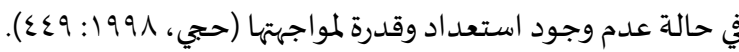

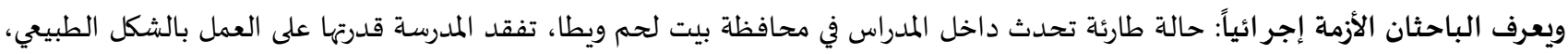

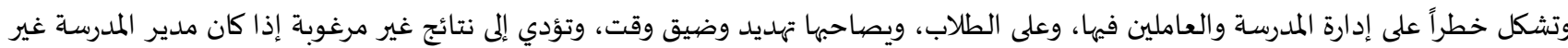

مستعداً لمواجهتها. إدارة الأزمة: نشاط هادف تقوم بها إدارة المدرسة لتفهم طبيعة المخاطر وأسبابها ومجرياتها ونتائجها لكي تحدد ما ينبغي عمله حيالها، واتخاذ وتنفيذ

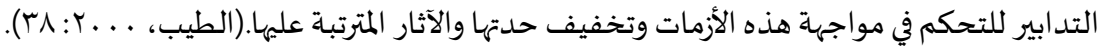

\section{الإطار النظري والدراسـات السـابقة:}

الإدارة التربوية في جوهرها عملية قيادية في المقام الأول ومقدرة على التأثير في الأفراد ودفعهم لإنجاز أهداف المؤسسة التربوية وأولوياتها والسعي الدائم لتطويرها (عماد الدين، • • ب). فهي من ميادين الإدارة التي أصبحت رئيسية لتحقيق أهداف العملية التربوية من خلال الاستخدام الأمثل

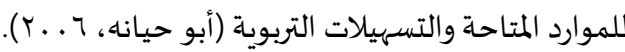
مفهوم الأزمة: نشأ مفهوم الأزمة أول ما نشأ في نطاق العلوم الطبية ،حيث يرجع إلى المصطلح اليوناني "كرينو" ويعني "نقطة تحول" وهي لحظة مرضية محددة

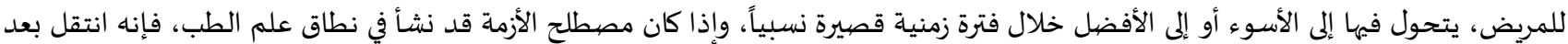

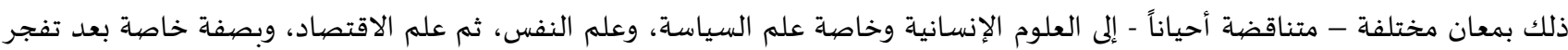

الأزمات الاقتصيادية.

وقد تعددت المفاهيم المختلفة للأزمة من وجهات نظر مختلفة. مع ذلك نجد صعوبة في الحصول على تعريف محدد لها، ولكن يمكن تعريفها من خلال خصائصها، فيرى البعض أن الأزمة عبارة عن خلل يؤثر تأثيراً مادياً على النظام كله، كما يهدد الافتراضات دهات الرئيسية التي يقوم عليها هذا النظام 
فالأزمة هي نقطة تحول غير عادياة، وحدث مفاجئ في حياة المنظمة يفقدها التوازن ويوقف تصرفاتها الطبيعية بشكل يصعب التكهن به، وبأبعاده

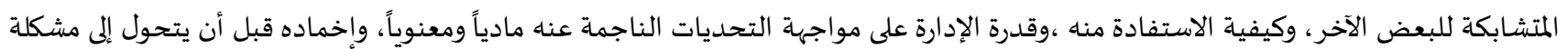

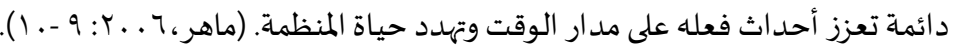

أسباب نشوء الأزمة:

لكل ازمة أسباب وعوامل تؤدي إلى نشوئها. ويرى عنتور(r ا ـr) أن أسباب نشوء الأزمات يعود إلى قلة المعلومات، وعدم وضوح الرؤية الكاملة

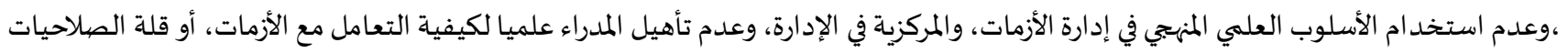

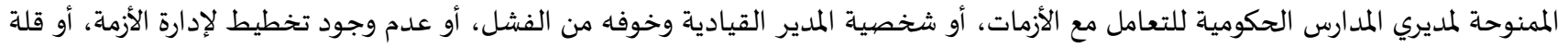

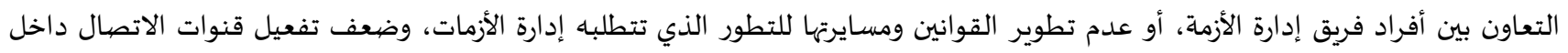

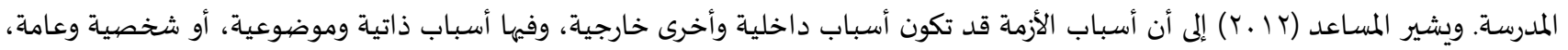

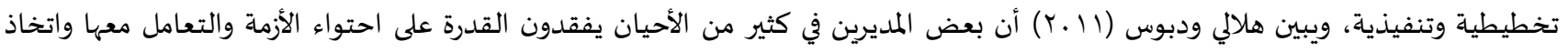

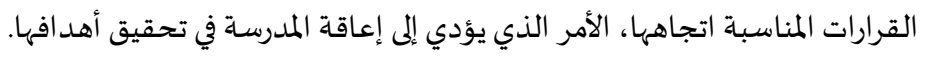
خصيائص إدارة الأزمات:

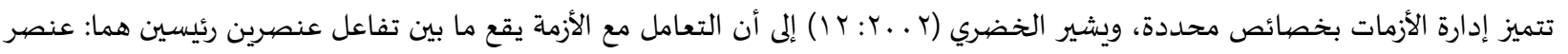

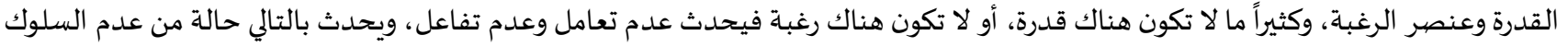

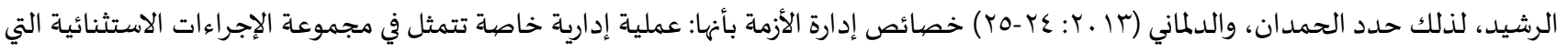
تتعدى الوصف الوظيفي المعتاد للمهام الإدارية، ووضع خطط معينة لمواقف الأزمات، وأن الأزمة تدار بواسطة مجموعاة من القدرات الإدارية الكفء

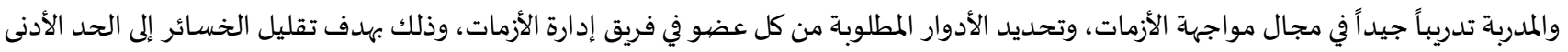
من تكاليف مواجهة الأزمات، من خلال استخدام الأسلوب العلمي في اتخاذ القرار.

وظائف إدارة الأزمة: هناك وظائف متعددة ومحددة مرتبطة مباشرة بإدارة الأزمة ،ويبين ميتاجنح (mitagang, 2012) أن هذه الوظائف تتمثل في: اختيار مدربين

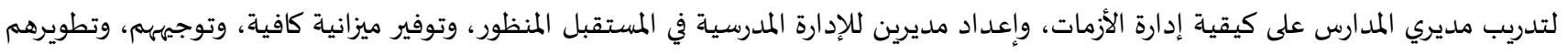
مهنياً وفقاً لاحتياجاتهم الفردية. مراحل الأزمة:

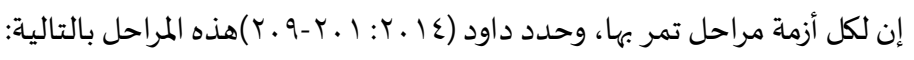
المرحلة الأولى: اكتشاف إشارات الإنذار، وهي إشارات تحذيرية مبكرة ومتكررة بصهورة دائمة.

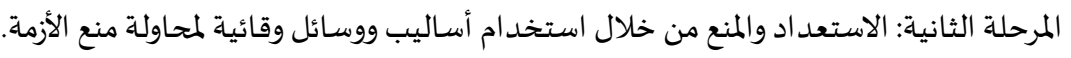
المرحلة الثالثة: احتواء الأضرار.

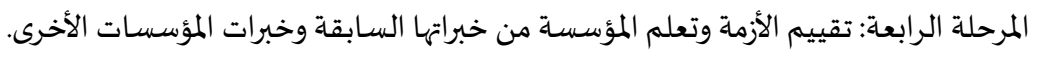

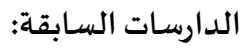
هدفت دراسة صراص (10 ـ ب) إلى التعرف على واقع إدارة الأزمات في المدارس الخاصة في محافظتي بيت لحم ورام الله والبيرة من وجه نظر المدراء

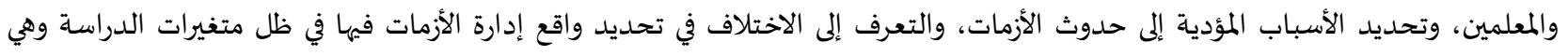
المحافظة، والجنس، والمؤهل العلمي، وعدد سنوات الخبرة، والمسمى الوظيفي. وقد تكون مجتمع الدراسة من جميع المديرين والمعلمين العاملين في

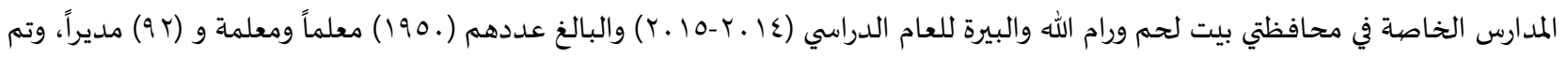

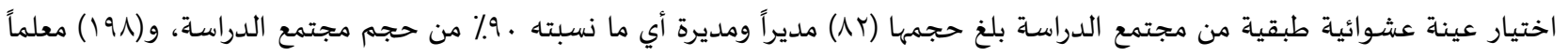

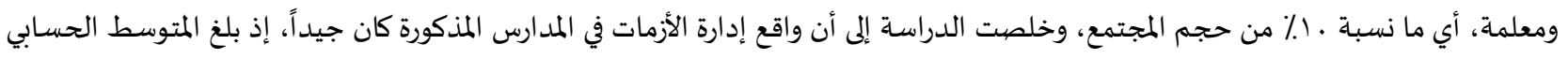

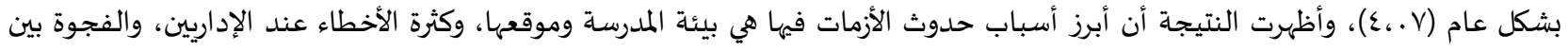

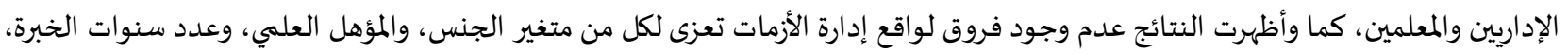
والمحافظة، وأظهرت وجود فروق تعزى لمتغير المسمى الوظيفي لصالح المديرين. و أجرى عنتور (r ا • r) دراسة هدفت التعرف إلى معوقات إدارة الأزمات وسب علاجها في المدارس الحكومية الثانوية في محافظات الضفة الغربية

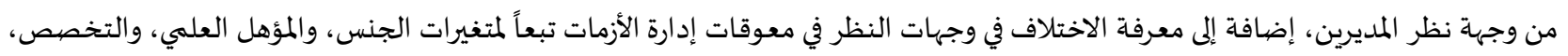


والخبرة الإدارية، والمحافظة، وعدد الدورات، وموقع المدرسة، وعدد طلبة المدرسة. تكون مجتمع الدارسة من جميع مديري المدارس الحكومية

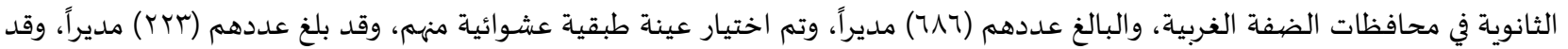
توصلت الدراسة إلى أن هناك درجة منخفضاة لمعوقات إدارة الأزمات في المدارس الحكومية الثانوية في محافظات الضفاة، إذ بلغ المتوسط الحسابي لها (9)، r) من وجهات نظر المديرين، كما لا توجد فروق ذات دلالة بين متوسطات وجهات نظر المديرين في مجالات ومعوقات إدارة الأزمات في المد ارس الثانوياة، تعزى لمتغيرات الجنس، والمؤهل العلمي، والتخصص، والخبرة، والمحافظة، وعدد الدورات الإدارية، وموقع المدرسة، وعدد طلبة الماتية

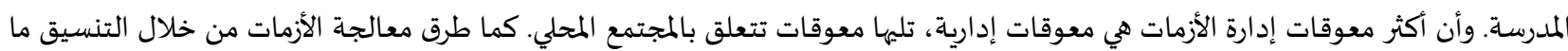
بين الجهاة المشرفة على حل الأزمات وأطراف الأزمة بشكل مباشر وقوي، وتكثيف التوعية الخاصية بالأزمات. وهدفت دراسة أبو معمر(1) الـ التعرف إلى دور مديريات التربية والتعليم في ادارة الأزمات التي تواجه مديري المدارس الحكومية في محافظات غزة

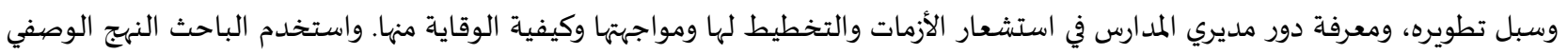

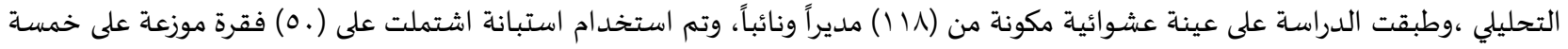
أبعاد، ومن أهم نتائج الدراسـة: ا. تقوم مديريات التربية والتعليم بممارسة إدارة الأزمات التعليمية بدرجة كبيرة.

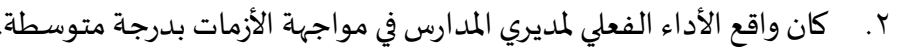

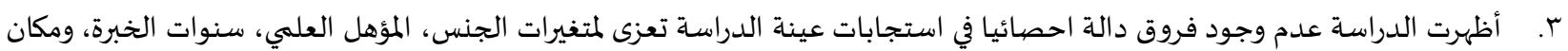
المديرية. وأوصت الدراسة بإنشاء قسم مختص بإد ارة الأزمات في كل مديريات التربية والتعليم في قطاع غزة. دراسـة علي ( 10 ـ هدفت الدراسة إلى التعرف على مشكلات الإدارة المدرسية خلال الأزمة الراهنة وعلاقتها بتأدية وظائفها الإدارية في المدارس الثانوية العامة في مدينة دمشق، ومن أجل تحقيق ذلك تم استخدام المنهج الوصفي التحليلي، وكما تم استخدام الاستبيان كأداة للدراسة حيث تم

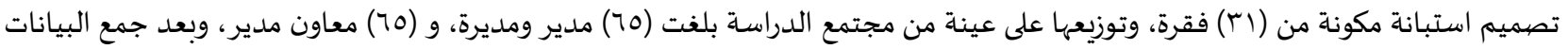

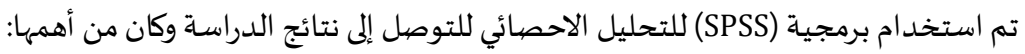

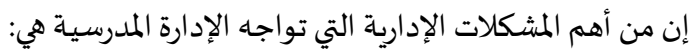

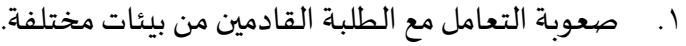

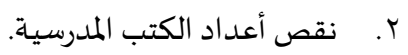
r. الحاجة لغرف صفية إضافية لتغطية الأعد اد المتزايدة للطلاب. ع. هعوبة تعويض تأخير المدرسين صباحاً. 0. نقص مستلزمات الإسعافات الأولية في المدرسة.

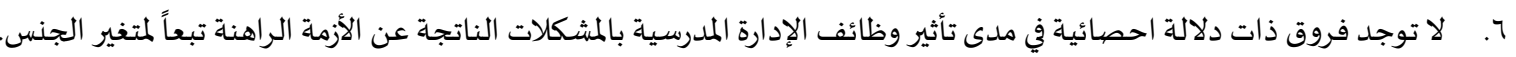

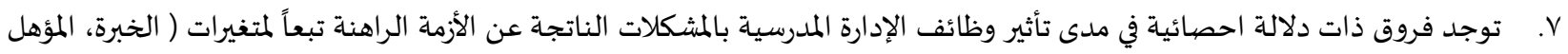
العلمي). بينما هدفت دراسـة لمينغ ( limig, 2010) إلى تعرف أهم المشكلات التي تواجاء مديري المدارس الثانوية في المدارس الحكومية في مقاطعة مانشستر في بريطانيا، في ضوء متغيرات الجنس والمؤهل العلمي والخبرة في العمل، وطبقت الدراسة على عينة من (rع) مديراً ومديرة وزعت عليهم استمارة شملت

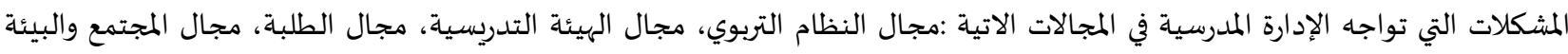
المحلية، وبعد تحليل البيانات أظهرت الدراسة النتائج الآتية:

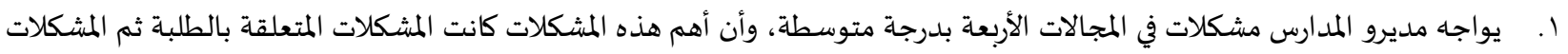

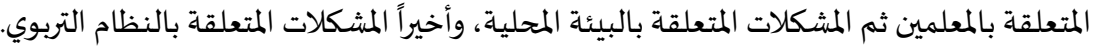

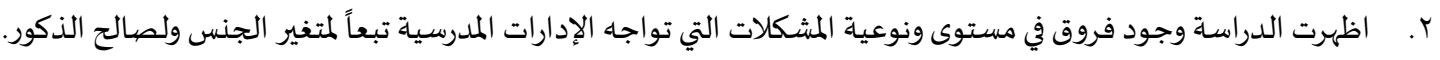
r. أظهرت الدراسة عدم وجود فروق في مستوى ونوعية المشكلات التي تواجه الإدارات المدرسية تبعاً لمتغيرات: المؤهل العلمي والخبرة في العمل. وهدفت دراسة القرني ( V . ا إلى تحديد أهم المشكلات التي تعاني منها الإدارة المدرسية في مدارس الأبناء بنين في مدينة الرياض ومعرفة إذا ما

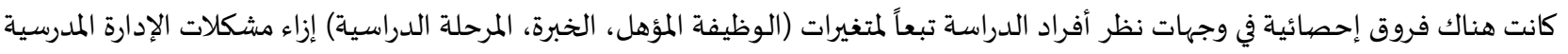
التي تعاني منها مدارس الأبناء في الرياض. 
واعتمدت الدراسة المنهج الوصفي حيث طبقت على جميع أفراد الدراسة وعددهم (VV)، وهم جميع المشرفين التربويين والمدراء والوكلاء بمدارس المارس

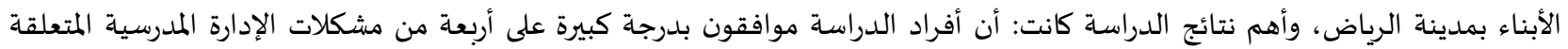

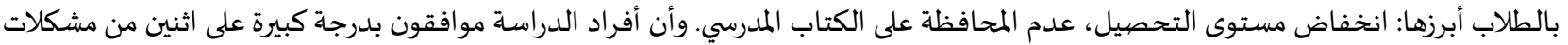

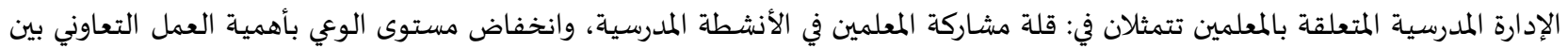

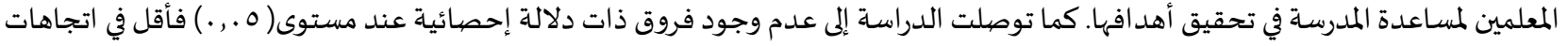

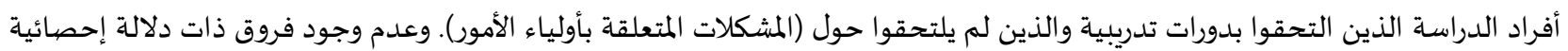

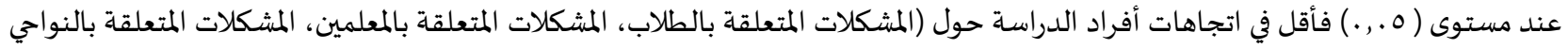

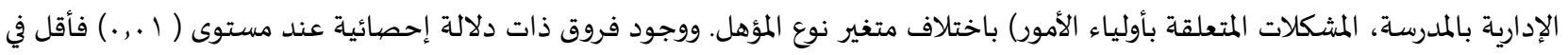

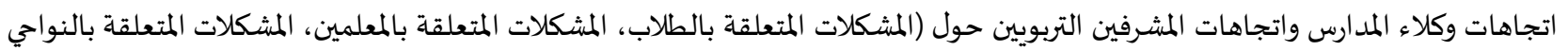

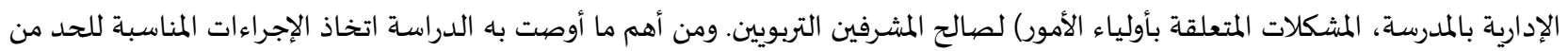
مشكلات الإدارة المدرسية والاهتمام بتحسين المستوى التحصيلي للطلاب.

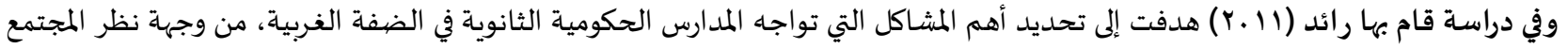

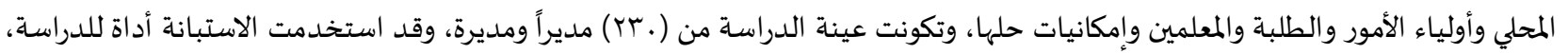

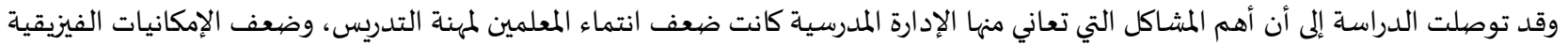
في المدارس، وعدم وجود تأهيل للمعلمين تربوياً.

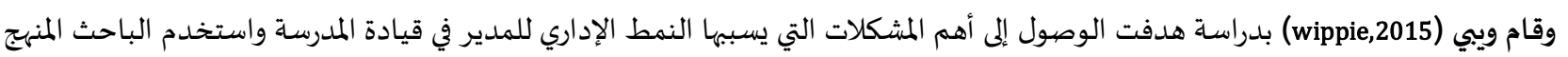

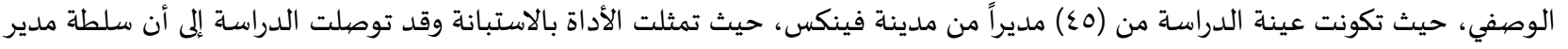

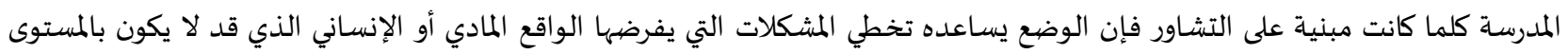
المأمول (النهج الديمقراطي) أن النمط الديمقراطي يزيد من الرضا لدى أعضاء هيئة التدريس، والنمط التسلطي يؤدي إلى النفور وخلق المشككلات

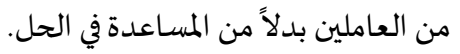

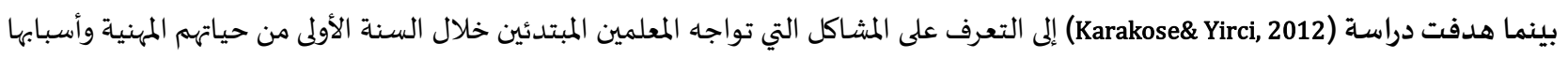
من خلال مقابلة أربعة وتسعين معلماً مبتدئ ممن لا تزيد خبرتهم التدريسية عن عامين من العاملين في محافظتي الازيج وكنهرمان مارس في تركيا، وتوصلت الدراسة إلى: ا. مواجهة غالبية المعلمين مشكلات نتيجة عدم كفاية برامج التعليم المقدمة لهم في كليات إعداد المعلم ومواقف مديري المدارس السلبية تجاههم. r أ. عدم وجود برامج للتوجيه تدعمهم وتمدهم بالخبرات المفقودة.

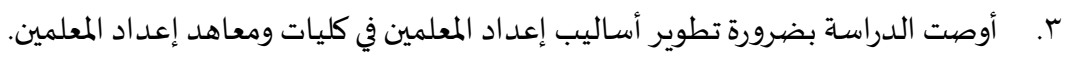

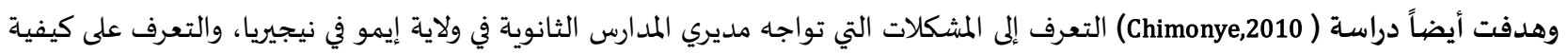

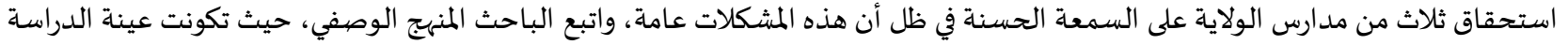

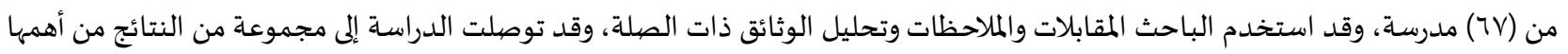

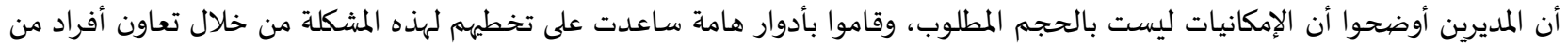

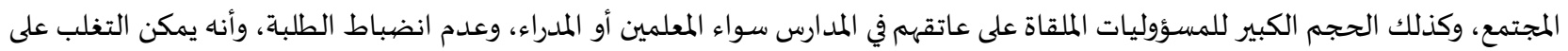
هذه المشكلة من خلال إظهار الممارسات المهنية والالتزام والشجاعة والتأكيد على المسؤولية الجماعية وانتهاج أساليب القيادة المختلفة ومنها

$$
\text { الأسلوب التركيبي الدبلوماسي. }
$$

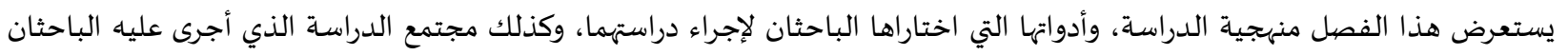

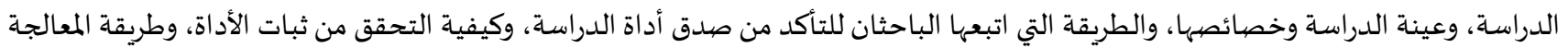


استناداً إلى طبيعة الدراسة وأهد افها استخدم الباحثان في الدراسة الحالية المنهج الوصفي التحليلي، وكذلك لملائمته لأهداف الدراسة وأسئلتهـ.

تكون مجتمع الدراسة من جميع المعلمين والمعلمات الذين يدرسون في المدارس الحكومية في مديرية التربية والتعليم /يطا ومديرية التربية والتعليم

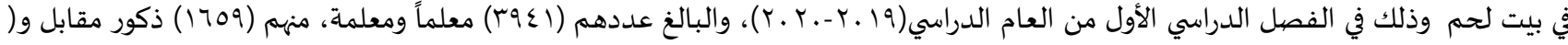

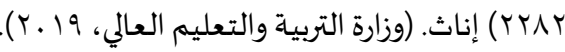
عينة الدراسة:

تم اختيار عينة الدراسة بالطريقة العشوائية البسيطة حيث تكونت عينة الدراسة من ( . ب) معلم ومعلمة منهم (Y ـ ( ) معلم و (191) معلمة

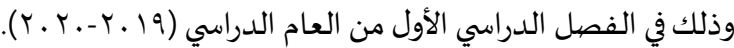

جدول(1): الأعداد، والنسب المئوية لخصبائص العينة الديموغر افية حسب الجنس والمؤهل العلمي وسنوات الخبرة و المديرية وموقع المدرسة

\begin{tabular}{|c|c|c|}
\hline النسبة المئوية & العدد & المتغيرات \\
\hline \multicolumn{3}{|c|}{ الجنس } \\
\hline$\% \varepsilon$ & $1 . r$ & ذكر \\
\hline$\% 77$ & 191 & اثنى \\
\hline$\% \ldots$ & $r .$. & المجموع \\
\hline \multicolumn{3}{|c|}{ المؤهل العلمي } \\
\hline \%.Ar & rol & بكالوريوس فما دون \\
\hline$\% 1 \mathrm{~V}$ & $\varepsilon 9$ & أعلى من بكالوريوس \\
\hline$\%$ & $r .$. & المجموع \\
\hline \multicolumn{3}{|c|}{ سنوات الخبرة } \\
\hline$\% \varepsilon r$ & $I T V$ & $0-1$ \\
\hline$\%$ \%० & $1 \% 0$ & $1 .-7$ \\
\hline$\%$ & $r \mu$ & 11سنة فأكثر \\
\hline$\%$ & $r .$. & المجموع \\
\hline \multicolumn{3}{|c|}{ المديرية } \\
\hline$\%$ & 10. & يطا \\
\hline$\%$ & 10. & بيت لحم \\
\hline$\%$ & $r .$. & المجموع \\
\hline \multicolumn{3}{|c|}{ موقع المدرسة } \\
\hline$\%$ & iv. & قرية \\
\hline$\% \varepsilon \varepsilon$ & ir. & مدينة \\
\hline$\%$ & $r .$. & المجموع \\
\hline
\end{tabular}

أداة الدراسـة:

تم استخدام أداة واحدة لجمع البيانات اللازمة للإجابة على أسئلة الدراسة وقد تم استخدام مقياس ليكرت الخماسي لقياس استجابات المبحوثين لفقرات الاستبيان حسب الجدول جدول (r) ): درجات مقياس ليكرت الخماسي

\begin{tabular}{|c|c|c|c|c|c|}
\hline بدرجة قليلة جداً & بدرجة قليلة & بدرجة متوسطة & بدرجة كبيرة & بدرجة كبيرة جداً & الاستجابة \\
\hline 1 & $r$ & $r$ & $\varepsilon$ & 0 & الدرجة \\
\hline
\end{tabular}

صدق أداة الدراسة: ا. صدق المحكمين: تم التحقق من صدق الأداة قبل عملية تطبيقها على عينة الدراسة بعرضها على مجموعة من المحكمين الذين أبدوا عدداً من

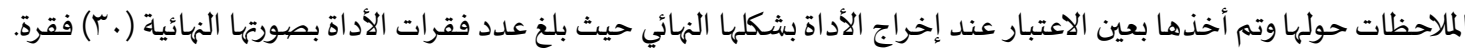
r. صدق التحليل العاملي: تم التحقق من الصدق بحسـاب التحليل العاملي (Factor Analysis) لفقرات الأداة ، وذلك كما هو واضح في الجدول (r) (r)

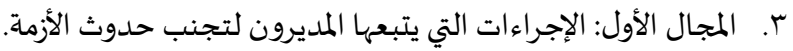


جدول (r): نتائج التحليل العاملي (Factor Analysis) لفقرات أداة الدراسة

\begin{tabular}{|c|c|c|}
\hline درجة التشبع & 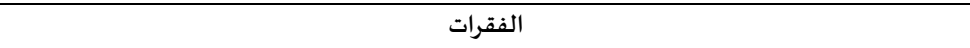 & 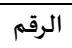 \\
\hline \multicolumn{3}{|c|}{ المجال الأول: الإجراءات التي يتبعها المديرون لتجنب حدوث الأزمة } \\
\hline$\cdot, 7$. & ينظم المدير اجتماعات مع المعلمين وأولياء الأمور لتفقد الأزمات الطلابية ومتابعتها لإيجاد الطرق المناسبة لتجنها. & 1 \\
\hline., 79 & ينشىء المدير صندوق شكاوي للطلاب للتعرف على ما يقلقهم. & r \\
\hline., 71 & يساهم المدير في تشكيل لجان الإصلاح لفض النزاعات بالطرق الودية بالتنسيق مع مؤسسات المجتمع المحلي & $r$ \\
\hline$\cdot, \mathrm{VT}$ & ينظم المدير ندوات ومحاضرات توعية وقائية للحد من الأزمات الطلابية في المدرسة & $\varepsilon$ \\
\hline$\cdot, \mathrm{VT}$ & يتعاون المدير مع مجالس الآباء في الحد من العادات والتقاليد الضارة مثل (التدخين ن والمخدرات ....الخ( & $\circ$ \\
\hline ז ז & يستفيد المدير من ذوي الخبرة والاختصاص في المجتمع المحلي لتجنب الأزمات & 7 \\
\hline., 7 . & ينظم المدير لقاءات مع الطلاب لمناقشة الأزمات المدرسية التي قد يواجهونها & $\mathrm{v}$ \\
\hline., 77 & يعالج المدير المشاحنات بين الطلاب ومعلميهم فور حدوثها في المدرسة. & $\Lambda$ \\
\hline$\cdot, 7$ & يشجح المدير المعلمين على الاجتماع بأولياء الأمور لمناقشة مشكلات أبنائهم والعمل على حلها. & 9 \\
\hline \multicolumn{3}{|c|}{ المجال الثاني : الإجراءات التي يتبعها المديرون في التخطيط لمواجهة الأزمة } \\
\hline.,$\pi$ & ينظم مدير المدرسة دورات للمعلمين والعاملين في المدرسة حول كيفية التعامل مع الأزمات & 1. \\
\hline$\cdot, \mathrm{VT}$ & يشكل مدير المدرسة فريقاً لمواجهة الأزمات التي قد تحدث في المدرسة. & 11 \\
\hline$\cdot, \mathrm{VI}$ & يراعي المدير توزيع الأدوار عند وقوع الأزمة. & ir \\
\hline$\cdot, 7$. & يشرك المدير المعلمين في المدرسة في تخطيط برامج مواجهة الأزمات. & ir \\
\hline., 70 & يحرص المدير على وضع خطة مسبقاً لاستخدامها عند حدوث الأزمة. & I乏 \\
\hline., $7 \varepsilon$ & يبادر المدير إلى جمع المعلومات الكافية والدقيقة المتعلقة بالأزمة. & 10 \\
\hline., 7 T & يهيئ المدير المعلمين والطلاب نفسياً للتعامل الإيجابي مع الأزمات. & 17 \\
\hline$\cdot, 71$ & يستفيد المدير من الخبرات السابقة في حل المشكلات الناجمة عن الأزمات. & IV \\
\hline .,VY & يحدد المدير البدائل المتاحة وقت حدوث الأزمة لاستخدام البديل الأمثل. & 11 \\
\hline$\cdot, \mathrm{VT}$ & يعد المدير جدول أولويات يتسم بالدقة لمواجهة الأزمات. & 19 \\
\hline 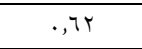 & يوفر المدير فريقاً متنوع التخصصات يختص بإدارة الأزمات في المدرسة. & r. \\
\hline \multicolumn{3}{|c|}{ المجال الثالث : الإجراءات التي يتبعها المديرون للتعامل مع الأزمة أثناء حدوثها } \\
\hline$\cdot, 71$ & يتخذ المدير قرارات حاسمة وسريعة حين حدوث الأزمات. & rI \\
\hline . VY & يتصف المدير بصفات وسمات شخصية تؤهله للسيطرة على الأزمة. & rr \\
\hline$\cdot, \mathrm{VT}$ & يتبنى المدير سياسة الباب المفتوح في مدرسته لمواجهة الأزمة. & rr \\
\hline . Tr & يستعين المدير بخبراء من خارج المدرسة لمعالجة الأزمات. & $r \varepsilon$ \\
\hline$\cdot, 7$ & يستثمر المدير الإمكانات المادية والبشربة الضروربة لاحتواء الأزمة. & ro \\
\hline., 77 & يعمل المدير على خفض حدة التوتر ورفع الروح المعنوية للعاملين والطلبة عند حدوث الأزمة. & r7 \\
\hline$\cdot, \mathrm{VT}$ & يحرص المدير على الحد من الشائعات في الحديث عن الأزمة حتى لا تتفاقم. & rV \\
\hline$\cdot, \mathrm{V}$ & يفعل المدير مبدأ تفويض الصلاحيات لمواجهة الأزمة. & rᄉ \\
\hline$\cdot, 7$. & يشيع المدير الطمأنينة بين العاملين والطلاب أثناء حدوث الأزمة. & r9 \\
\hline$\cdot, 70$ & يحدد المدير المهام والمسؤوليات والصلاحيات عند حدوث الأزمة & $r \cdot$ \\
\hline
\end{tabular}

تشير المعطيات الواردة في الجدول (r) أن التحليل العاملي لجميع فقرات أداة الدراسة دال إحصائياً، وتتمتع بدرجة مقبولة من التشبع، وأهها

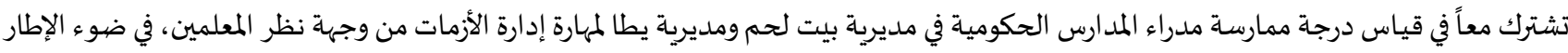
النظري الذي بنيت الأداة من أجله.

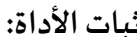

تم حساب الثبات لأداة الدراسة بأبعاده المختلفة بطريقة الاتساق الداخلي بحساب معادلة الثبات (Cronbach's Alpha Coefficient) ، وكانت

النتائج كما هي مبينة في جدول (ع).

جدول (ع): معامل كرونباخ ألفا لقياس ثبات أداة الدراسة

\begin{tabular}{|c|c|c|c|c|}
\hline القيمة الاحتمالية (Sig.) & قرونباخ ألفا & الفقرات & أبعاد الدراسة & الرقم \\
\hline$*_{0}^{*}, \ldots$ &., 947 & 9 & الإجراءات التي يتبعها المديرون لتجنب حدوث الأزمة & 1 \\
\hline$*_{., \ldots}$ & .909 & 11 & الإجراءات التي يتبعها المديرون في التخطيط لمواجهة الأزمة & r \\
\hline${ }^{*}, \ldots$ & .974 & 1. & الإجراءات التي يتبعها المديرون للتعامل مع الأزمة أثناء حدوثها & r \\
\hline${ }^{*}, \ldots$ &., 9 , १Y & $r$. & الدرجة الكلية & $\varepsilon$ \\
\hline
\end{tabular}

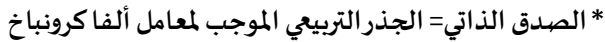


تشير المعطيات الواردة في الجدول (ع) أن أداة مهارة إدارة الأزمة بأبعادها المختلفة تتمتع بدرجة عالية من الثبات، إذ بلغت الدرجة الكلية لثبات

تتضمن هذه الأداة درجة ممارسة مدراء المدارس الحكومية في مديرية بيت لحم ومديرية يطا لمهارة إدارة الأزمات من وجهة نظر المعلمين، وقد بنيت الفقرات حسب سلم خماسي وأعطيت الأوزان للفقرات كما هو آت: (بدرجة كبيرة جداً: خمس درجات، بدرجة كبيرة: أرع درجات، بدرجة متوسطة: ثلاث

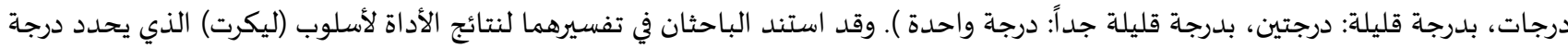

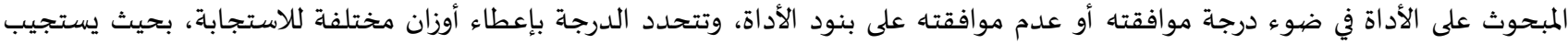

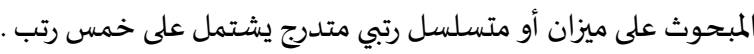

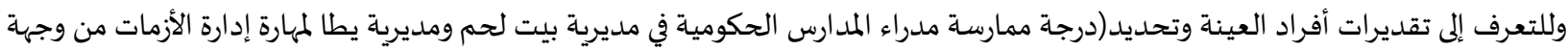

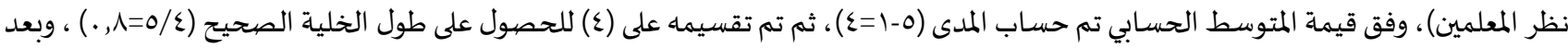

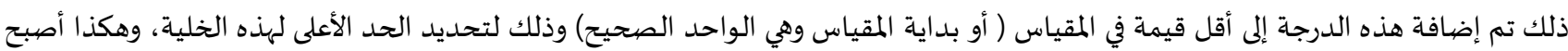

طول الخلايا كما في جدول (o).

جدول (0): مفتاح المتوسطات الحسابية، وطول الخلايا

\begin{tabular}{|c|c|c|}
\hline درجة الموافقة & الوزن النسبي & المتوسط الحسابي \\
\hline قلية جداً & |كبر .r-צr/| & من 1, 1, 1 \\
\hline قليلة & 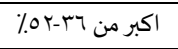 & 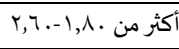 \\
\hline متوسطة & 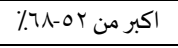 & 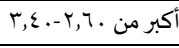 \\
\hline كبيرة & 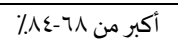 & أكبر من .\&, . \\
\hline كبيرة جداً & أكبر من عـ-... 1. & أكبر من . . \\
\hline
\end{tabular}

المعالجة الإحصيائية للبيانات:

بعد جمع بيانات الدراسة قام الباحثان بمراجعتها تمهيداً لإدخالها للحاسوب، وإعطائها أرقاماً معينة، أي بتحويل الإجابات اللفظية إلى رقمية،

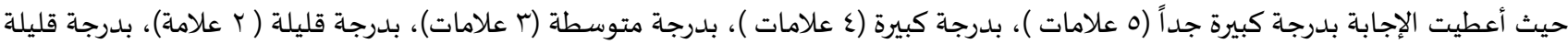

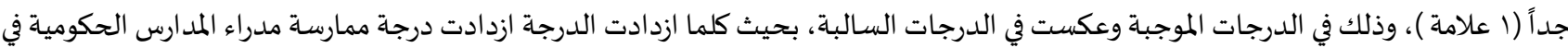
مديرية بيت لحم ومديرية يطا لمهارة إدارة الأزمات من وجهاة نظر المعلمين وقد تم استخدام الأدوات الإحصائية التالية:

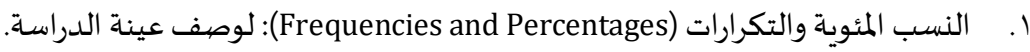
r r. المتوسط الحسابي، والمتوسط الحسابي النسبي، والانحراف المعياري.

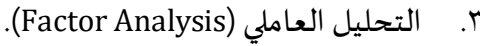
ع. اختبار ألفا كرونباخ (Cronbach's Alpha) لمعرفة ثبات فقرات الاستبانة. 0. معامل ارتباط بيرسون (Pearson Correlation Coefficient) 7. اختبار T في حالة عينتين (Independent Sample T- Test) معرفة ما إذا كانت هناك فروقات ذات دلالة إحصائية بين مجموعتين من البيانات المستقلة.

V اختبار تحليل التباين الأحادي (One Way Analysis of Variance - ANOVA) لمعرفة إذا كانت هناك فروقات ذات دلالة إحصائية بين ثلاث مجموعات أو أكثر من البيانات. وقد استخدمه الباحثان للفروق التي تعزى للمتغير والذي يشتمل على ثلاث مجموعات فأكثر.

إجراءات تطبيق الدراسـة:

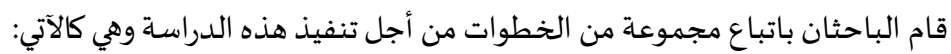
قام الباحثان بحصر مجتمع الدراسـة والمتمثل في المعلمين الذين يدرسون في المدارس الحكومية في مديريات محافظة بيت لحم ويطا، وعليها تم بناء

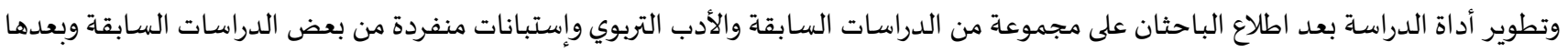
قام الباحثان بعمل مجموعة من الخطوات الفنية والتي تتيح إلى الباحثان القيام بتطبيق هذه الدراسة وذلك من خلال الحصول على موان موافقة من

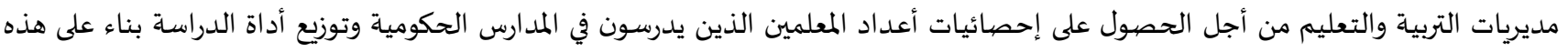

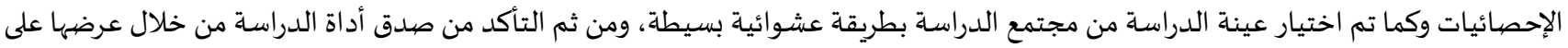

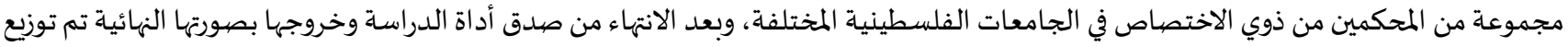




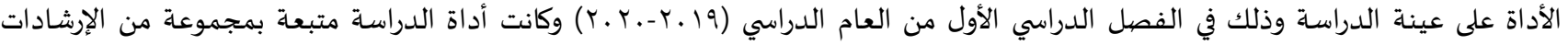

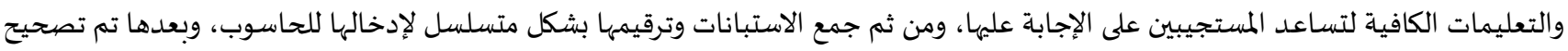
الأداة وتفريخ البيانات وتعبئتها في نماذج خاصة وذلك من خلال (برنامج الرزم الإحصائية للعلوم الاجتماعية spss) لتحليل البيانات واستخراج النتائج.

\section{تحليل النتائج:}

تمهيد

يتضمن هذا الفصل عرضاً كاملاً ومفصلاً لنتائج الدراسة, للتعرف على درجة ممارسة مدراء المدارس الحكومية في مديرية بيت لحم ومديرية يطا لمهارة إدارة الأزمات من وجهة نظر المعلمين, وذلك من خلال الإجابة عن أسئلة الدراسـة وأهدافها واختبار فرضياتها باستخدام التقنيات الإحصائية

المناسبة.

نتائج السؤال الرئيس: ما درجة ممارسة مدراء المدارس الحكومية في مديرية بيت لحم ومديرية يطا لمهارة إدارة الأزمات من وجهة نظر المعلمين ؟

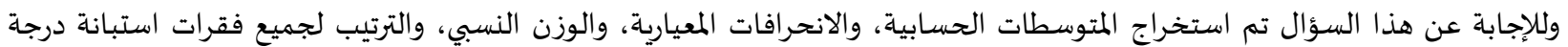

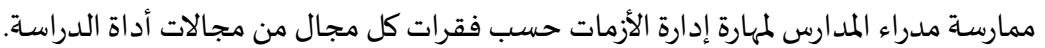
تحليل فقرات أداة "درجة ممارسة مدراء المدارس الحكومية في مديرية بيت لحم ومديرية يطا لمهارة إدارة الأزمات من وجهة نظر المعلمين".

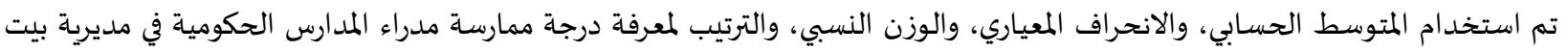

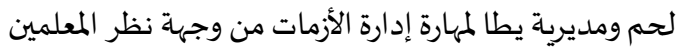
جدول ( 7): المتوسط الحسابي والانحراف المعياري والوزن النسبي والترتيب لكل فقرة من الفقرات " المجال الأول : " الإجراءات التي يتبعها المديرون لتجنب حدوث الأزمة"

\begin{tabular}{|c|c|c|c|c|c|c|}
\hline 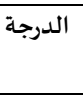 & الترتيب & الوزن النسبي & 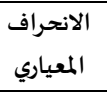 & المتوسط المسبي & 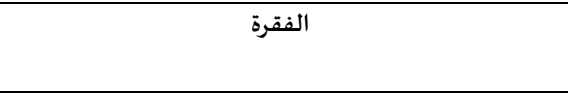 & 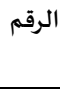 \\
\hline كبيرة & 1 & $\wedge \uparrow, \wedge \varepsilon$ & $\cdot, \mathrm{VV}$ & $\varepsilon, 19$ & 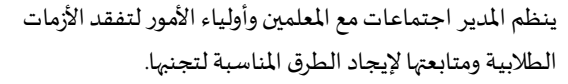 & 1 \\
\hline كبيرة & 9 & $V V, \varepsilon V$ & $\cdot, \lambda$. & $r, \wedge \mathrm{V}$ & ينشئ المدير صندوق شكاوي للطلاب للتعرف على ما يقلقهم. & $r$ \\
\hline كبيرة & $\circ$ & ᄉ., IV & $\cdot, 94$ & $\varepsilon, .1$ & الودية بالتنسيق مع مؤسسات المدير في تشكيل لجان الإصلاح لفض المحلي النزاعات بالطرق & $r$ \\
\hline كبيرة & 7 & $\vee १, \wedge$ & $\cdot, \lambda \mathrm{V}$ & $r, १ 9$ & ينظم المدير ندوات ومحاضرات توعية وقائية للحد من الأزمات & $\varepsilon$ \\
\hline كبيرة & r & 个r,ov & $\cdot, 10$ & $\varepsilon, 11$ & 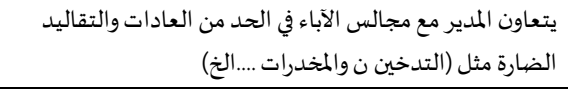 & $\circ$ \\
\hline كبيرة & $r$ & งr,qr & $\cdot, \wedge \varepsilon$ & $\varepsilon, 10$ & لتجنب الأزمات المدير من ذوي الخبرة والاختصهاص في المجتمع المحلي & 7 \\
\hline كبيرة & $\varepsilon$ & $11, .9$ & $\cdot, 17$ & $\varepsilon, .0$ & يوجهم المدير لقاءات مع الطلاب لمناقشة الأزمات المدرسية التي قد & v \\
\hline كبيرة & $\varepsilon$ & $11, .9$ & $\cdot, \lambda)$ & $\varepsilon, .0$ & يعالج المدير المشاحنات بين الطلاب ومعلمهيهم فور حدوثها في & $\wedge$ \\
\hline كبيرة & v & $V q, 0 \varepsilon$ & $\cdot, 19$ & $r, 91$ & 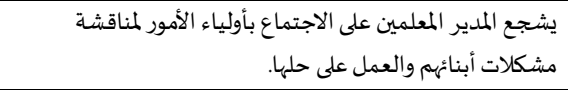 & 9 \\
\hline \multicolumn{4}{|c|}{ كبيرة } & $\varepsilon, .0$ & الدرجة الكلية & \\
\hline
\end{tabular}

جاءت الدرجة الكلية للمجال الأول بمتوسط حسابي قدره (0. ع) وبدرجة كبيرة.

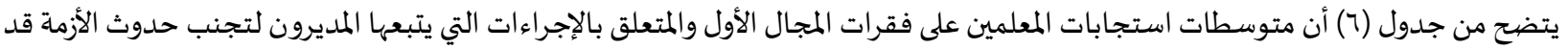
تراوحت بين (

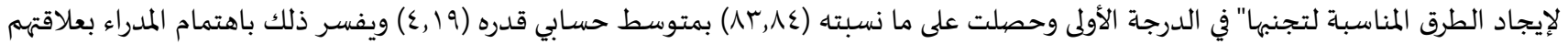

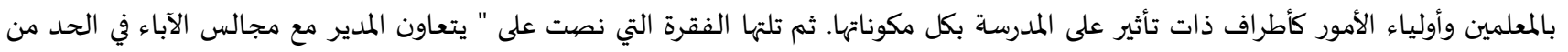

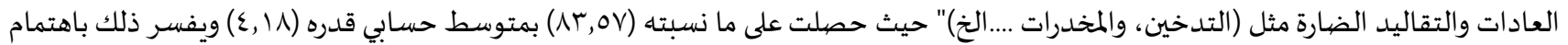
مدراء المدارس بمكافحة العادات السيئة التي قد يسلكها التلاميذ مما يسبب الضبرر لهم ويؤثر على سلوكهم وتحصيلهم الدراسي. أما أقل الفقرات موافقة في هذا المجال فكانت " ينشئ المدير صندوق شكاوي للطلاب للتعرف على ما يقلقهم". حيث حصلت على ما نسبتا (VV,V乏) بمتوسط حسابي 
قدره (V,Y)، مما يستدعي أن يتم حث المدراء على الاهتمام بهذا الأمر بدرجة أكبر مما هو عليه في الواقع وذلك من خلال إنشاء صندوق شكاوي للتعرف

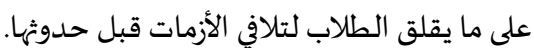

تم استخدام المتوسط الحسابي، والانحراف المعياري والوزن النسبي والترتيب لمعرفة درجة الموافقة والنتائج موضحة في جدول (7) جدول (V) :المتوسط الحسابي والانحراف المعياري والوزن النسبي والترتيب لكل فقرة من الفقرات مجال " الإجراءات التي يتبعها المديرون في التخطيط لمواجهة

الأزمة " لأبعرة

\begin{tabular}{|c|c|c|c|c|c|c|}
\hline 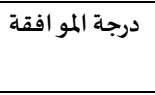 & الترتيب & الوزن النسبي & الانحراف المعياري & الحتوسط المسابي & 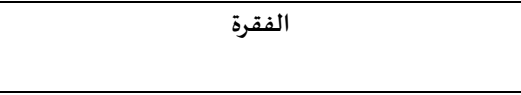 & 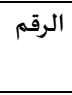 \\
\hline 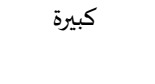 & 7 & $\Lambda, r \varepsilon$ & 促 & $\varepsilon, . r$ & حول كيفية التعامل مع الأزمات لمعدمات دلمين والعاملين في المدرسة & 1 \\
\hline كبيرة & 9 & $V, \cdot . T$ &., 91 & $r, 10$ & المدرسة، مدير المدرسة فريقاً لمواجهة الأزمات التي قد تحث في & r \\
\hline كبيرة & r & $\Lambda 1, \lambda r$ &., $\mathrm{~V} 7$ & $\varepsilon, .9$ & يراعي المدير توزيع الأدوار عند وقوع الأزمة. & $r$ \\
\hline كبيرة & $\wedge$ & $\Lambda ., .7$ & $\cdot, \Lambda \mathrm{V}$ & $\varepsilon, \ldots$ & يشرك المدير المعلمين في المدرسة في تخطيط برامج مواجهة & $\varepsilon$ \\
\hline 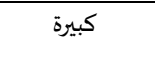 & $\varepsilon$ & $\Lambda \cdot, \wedge$. & $\cdot, \wedge$ & $\varepsilon, . \varepsilon$ & يحرص المديرة على وضع خطة مسبقاً لاستخدامها عند & 0 \\
\hline كبيرة & $r$ & $\wedge 1, \lambda \uparrow$ & $\cdot, \lambda r$ & $\varepsilon, .0$ & بالأزمةر المدير إلى جمع المعلومات الكافية والدقيقة المتعلقة & 7 \\
\hline كبيرة & 1. & $v_{\varepsilon, V_{0}}$ & $1, \cdot \mathrm{V}$ & $r, v \varepsilon$ & يهئ المدير المعلمين والطلاب نفسياً للتعامل الإيجابي مع & $\mathrm{r}$ \\
\hline كبيرة & 11 & $V \varepsilon, 09$ & $\cdot, 91$ & $r, v r$ & 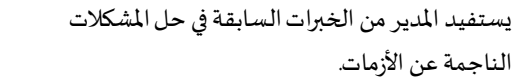 & $\wedge$ \\
\hline كبيرة جداً & 1 & 9 9 १, & $\cdot, \wedge 1$ & $\varepsilon, V r$ & يحدد المدير البدائل المتاحة وقت حدوث الأزمة لاستخدام & 9 \\
\hline كبيرة & 0 & A., IT & . & $\varepsilon, . r$ & يعد المدير جدول أولويات يتسم بالدقة لمواجهة الأزمات. & 1. \\
\hline كبيرة & $\mathrm{v}$ & $\wedge 1,9 r$ &., 91 & $\varepsilon, .1$ & في المدرسرة المدير فريقاً متنوع التخصصيات يختص بإدارة الأزمات & 11 \\
\hline & & & & $\varepsilon, \cdot r$ & الدرجة الكلية & \\
\hline
\end{tabular}

جاءت الدرجة الكلية للمجال الثاني بمتوسط حسابي قدره ( . ., ) وبدرجة كبيرة.

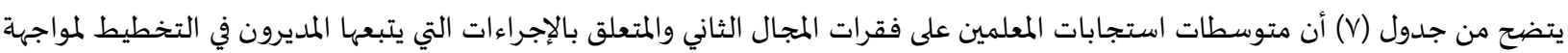

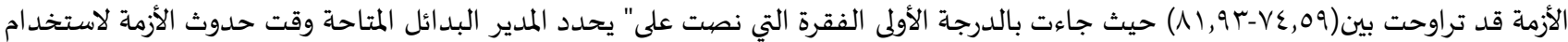

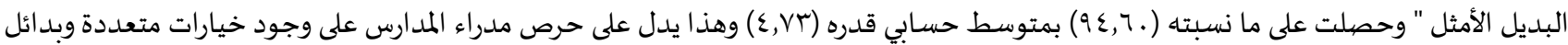

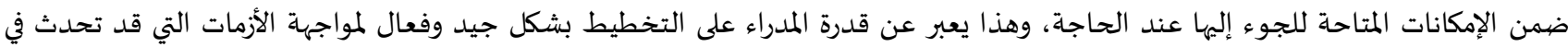

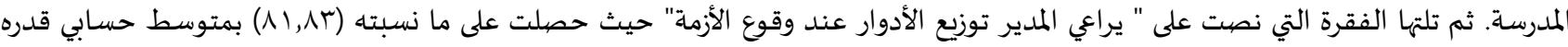

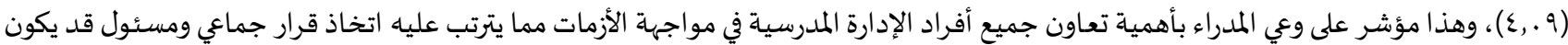
أقرب إلى الصواب. أما أقل الفقرات موافقة في هذا المجال فكانت "يستفيد المدير من الخبرات السـابقة في حل المشكلات الناجمة عن الأزمات " حيث

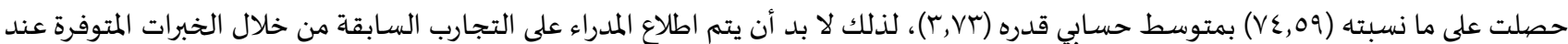

الجهات ذات العلاقة وحث المدراء على الاستفادة منها عند وقوع الأزمات.

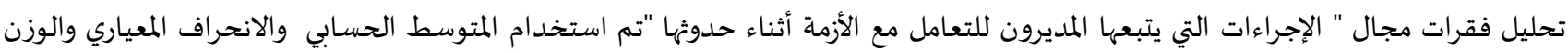

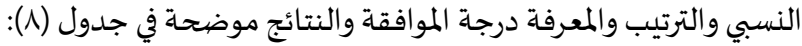


جدول (^): المتوسط الحسابي والانحراف المعياري والوزن النسبي والترتيب لكل فقرة من فقرات مجال " الإجراءات التي يتبعها المديرون للتعامل مع الأزمة أثناء حدوثها

\begin{tabular}{|c|c|c|c|c|c|c|}
\hline درجة المو افقة & الترتيب & الوزن النسبي & الانحراف المعياري & المتوسط الحسـابي & الفقرة & الرقم \\
\hline كبيرة & 1 & $\lambda r, 01$ & $\cdot, \wedge \vee$ & $\varepsilon, 11$ & الأزمات. & 1 \\
\hline كبيرة & 1. & $V V, \varepsilon 7$ & $\cdot, \wedge \vee$ & r,AV & على الأزمة المدير بصفات وسمات شخصية تؤهله للسيطرة & r \\
\hline كبيرة & $\varepsilon$ & $\vee १, १ \leq$ & . , Ar & $\varepsilon, \ldots$ & يتبنى المدير سياسة الباب المفتوح في مدرسته لمواجهة & $r$ \\
\hline 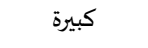 & $r$ & NI,rT & $\cdot, \wedge \varepsilon$ & $\varepsilon, . V$ & يستعين المدير بخبراء من خارج المدرسـة لمعالجـة الأزمات. & $\varepsilon$ \\
\hline كبيرة & 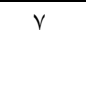 & VA, l. & . , ^ & $r, q$. & لاحتواء الأزمة. & 0 \\
\hline كبيرة & 9 & $V V, \varepsilon V$ & $\cdot, 9$. & $r, \wedge V$ & 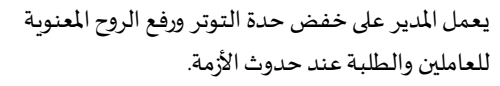 & 7 \\
\hline كبيرة & 0 & $\vee १, \vee \vee$ & $\cdot, \wedge 9$ & $r, 99$ & يحرص الممدير على الحد من الشائعات في الحديث عن & v \\
\hline كبيرة & $\Lambda$ & $V V, 09$ &., 9 . & $r, \wedge \Lambda$ & يفعل المدير مبدأ تفويض الصلاحيات لمواجهة الأزمة. & $\Lambda$ \\
\hline كبيرة & 7 & VA, rr & - & $r, q r$ & يشيع المدير الطمأنينة بين العاملين والطلاب أثناء حدوث & 9 \\
\hline كبيرة & r & Ar,TV & $\cdot, \wedge$. & $\varepsilon, 1 T$ & يحدد المدير المهام والمسؤوليات والصهلاحيات عند حدوث & 1. \\
\hline \multicolumn{4}{|c|}{ كبيرة } & $r, 91$ & \multicolumn{2}{|l|}{ 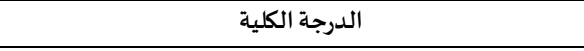 } \\
\hline
\end{tabular}

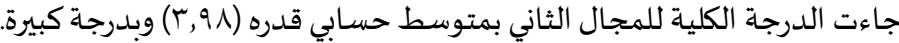
يتضيح من جدول (^) أن متوسطات استجابات المعلمين على فقرات المجال الثالث والمتعلق بالإجراءات التي يتبعها المديرون للتعامل مع الأزمة أثناء

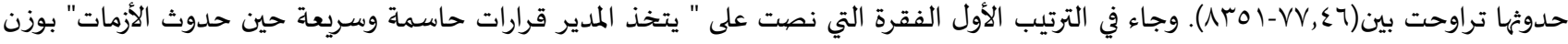

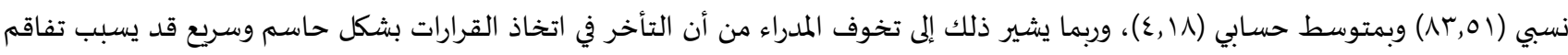
للأزمات مما يؤدي إلى نتائج قد يصعب معها الوصول لحلول لها، وكذلك فإن التعامل بشكل حاسمى مع الأزمات قد يكون له مردود ايجابي يتمثل في تلافي

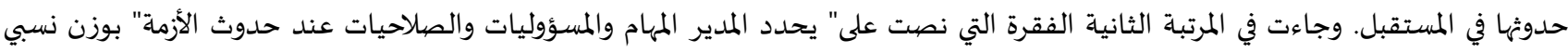

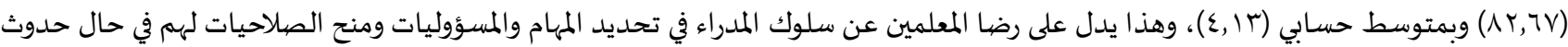
الأزمات مما يؤدي إلى رفع نسبة مساهمتهم، ويزيد من دافعيتهم من خلال المشاركة الفاعلة لمواجهة الأزمات حال حدوثها. وجاءت أخيراً الفقرة التي نصهيا

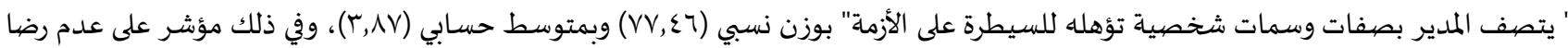
المعلمين بشكل كاف عن صفات المدير الشخصية مما يسترعي انتباه الجهات ذات العلاقة بالعمل على تنمية شخصيات المدراء من خلال عقد دورات وورش عمل حول الصفات التي تؤهلهم للسيطرة على الأزمات ومواجهنها.

اختبارفرضيات الدراسة:

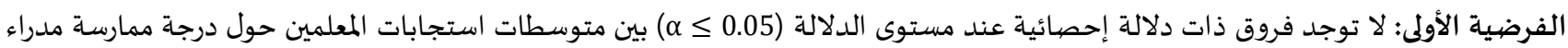

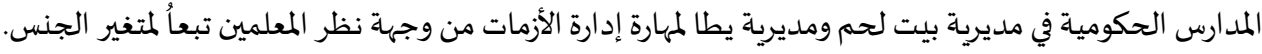

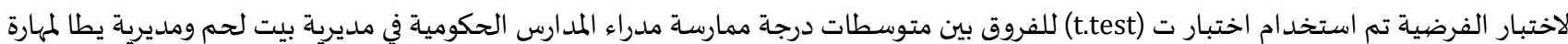

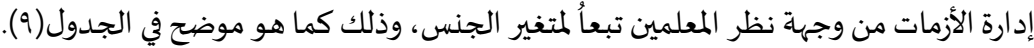


جدول (9) : نتائج اختبارت (t.test) للفروق بين متوسطات درجة ممارسة مدراء المدارس الحكومية في مديرية بيت لحم ومديرية يطا لمهارة إدارة الأزمات من

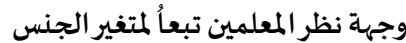

\begin{tabular}{|c|c|c|c|c|c|c|}
\hline الدالة الإحصائية & قيمة ت المحسوبة & درجات الحرية & الانحراف المعياري & الحستوسط & 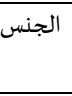 & المجالات \\
\hline \multirow[t]{2}{*}{. TIET } & \multirow[t]{2}{*}{$1,1 \vee 0$} & \multirow[t]{2}{*}{$\varepsilon 7 r$} &.,$\leq \varepsilon$ & $\varepsilon, \mid V$ & ذكر & \multirow{2}{*}{ 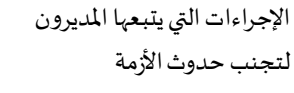 } \\
\hline & & &.,$\leqslant 9$ & $\varepsilon, .1$ & أنثى & \\
\hline \multirow[t]{2}{*}{$*_{.}, \ldots \varepsilon$} & \multirow[t]{2}{*}{$r, q . q$} & \multirow[t]{2}{*}{$\varepsilon 7 T$} & $\cdot, \varepsilon V$ & $r, \wedge \varepsilon$ & ذكر & \multirow{2}{*}{ التخطريط لمواجهة الأزمة المديرون في } \\
\hline & & & r & $r, 7 r$ & أنثى & \\
\hline \multirow[t]{2}{*}{$*_{.}, \ldots$} & \multirow[t]{2}{*}{$\varepsilon, q \uparrow .-$} & \multirow[t]{2}{*}{$\varepsilon 7 r$} & $\cdot, \mathrm{VA}$ & $r, \mathrm{VA}$ & ذكر & \multirow{2}{*}{ اللتعامل مع الأزمة أثناء حدوثهاء المداء } \\
\hline & & &., 7 . & $r, r r$ & أنثى & \\
\hline \multirow[t]{2}{*}{.,.人r } & \multirow[t]{2}{*}{$r, \ldots \varepsilon$} & \multirow[t]{2}{*}{ 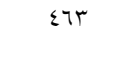 } &., 07 & $r, 09$ & ذكر & \multirow[t]{2}{*}{ الدرجة الكلية } \\
\hline & & &., 01 & $r, 71$ & أنثى & \\
\hline
\end{tabular}

تشير النتائج في الجدول أعلاه إلى عدم وجود فروق ذات دلالة إحصائية تبعاً لمتغير الجنس في المجال الأول المتعلق بالإجراءات التي يتبعها المديرون

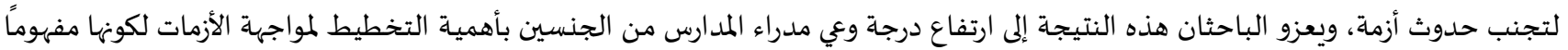

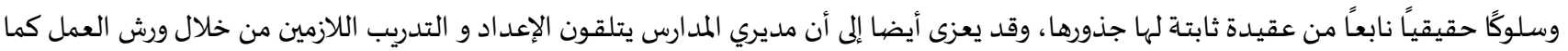

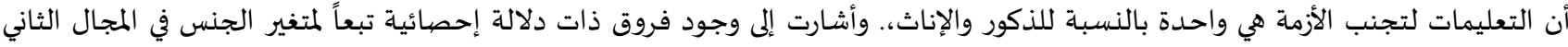

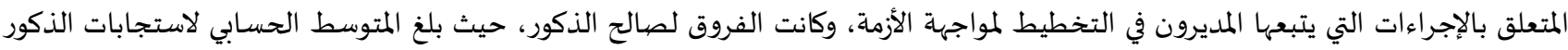

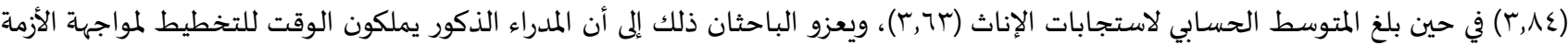

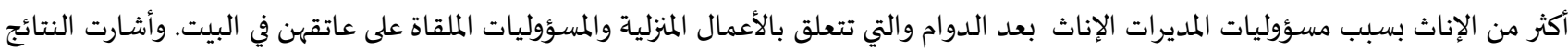

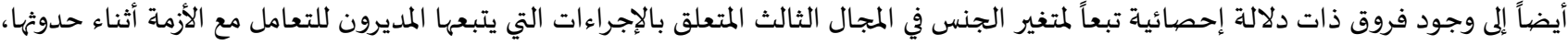

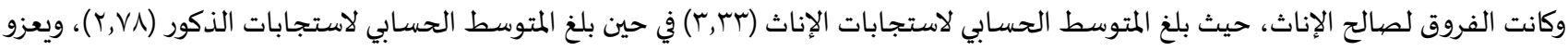

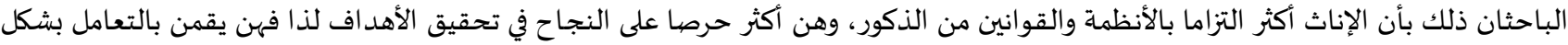

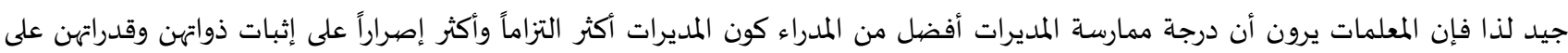

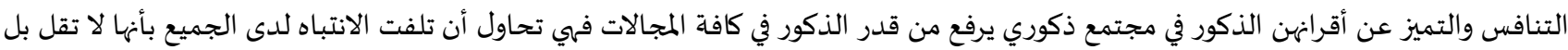

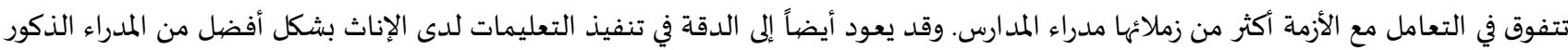

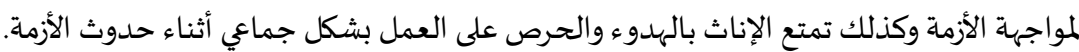

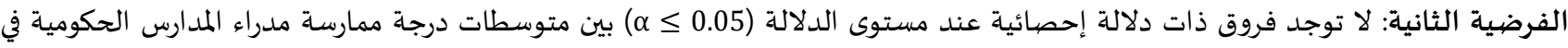

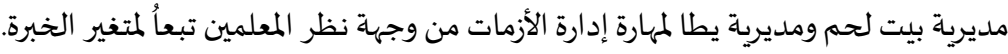

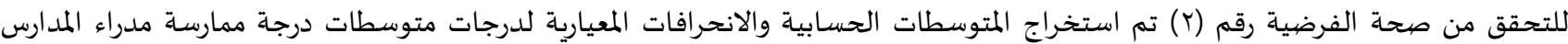

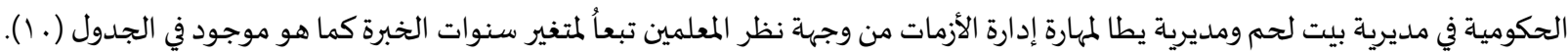
جدول (ـ ا) المتوسطات الحسابية والانحر افات المعيارية لدرجات تقديرات معلمي المدارس بين متوسطات درجات درجة ممارسة مدراء المدارس الحكومية في

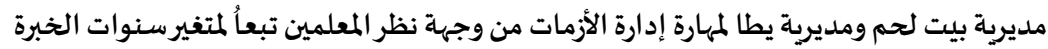

\begin{tabular}{|c|c|c|c|}
\hline الانحراف المعياري & المتوسط الحسابي & سنوات الخبرة & المجالات \\
\hline.,$\varepsilon r$ & $\varepsilon, . \wedge$ & $0-1$ & \multirow[t]{2}{*}{ الإجراءات التي يتبعها المديرون لتجنب حدوث الأزمة } \\
\hline., \&0 & $\varepsilon, r$. & $1 .-7$ & \\
\hline.,$T V$ & r,Vo & $0-1$ & \multirow{2}{*}{ الأإزمراءات التي يتبعها المديرون في التخطيط لمواجهة } \\
\hline., 0 & $\Gamma, \Lambda \varepsilon$ & $1 .-7$ & \\
\hline., 77 & $r, \ldots$ & $0-1$ & \multirow{3}{*}{ حلإِجراءات التي يتبعها المديرون للتعامل مع الأزمة أثناء } \\
\hline$\cdot, V V$ & $r, 1 \varepsilon$ & $1 .-7$ & \\
\hline$\cdot, \vee \vee$ & $r, 11$ & | 1 سنة فأكثر & \\
\hline.,$£ \wedge$ & $r, 71$ & $0-1$ & الدرجة الكلية \\
\hline
\end{tabular}


جدول (11): نتائج اختبارتحليل التباين الأحادي (one way analysis of variance) للفروق في متوسطات درجة ممارسة مدراء المدارس الحكومية في مديرية

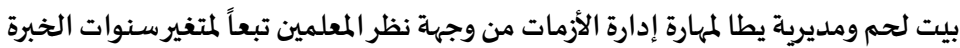

\begin{tabular}{|c|c|c|c|c|c|c|}
\hline الدلالة الإحصائية & المحسيوبة F Fمة & متوسط المربعات & مجموع المربعات & درجات الحرية & مصدر التباين & المجالات \\
\hline \multirow[t]{3}{*}{$.01 T$} & \multirow[t]{3}{*}{.,$T V}$. &., 101 &.,$r \cdot r$ & $r$ & بين المجموعات & \multirow{3}{*}{ الأزمة الإجراء التي يتبعها المديرون لتجنب حدوث } \\
\hline & & . & ro,ril & $\varepsilon 7 \pi$ & داخل المجموعات & \\
\hline & & $\ldots \ldots \ldots$ & $r 0,0 \mid \varepsilon$ & $\varepsilon 70$ & المجموع & \\
\hline \multirow[t]{3}{*}{. $1 \wedge \varepsilon$} & \multirow[t]{3}{*}{1,211} &., $\mathrm{rTh}$ &., $\mathrm{VTT}$ & $r$ & بين المجموعات & \multirow{3}{*}{ 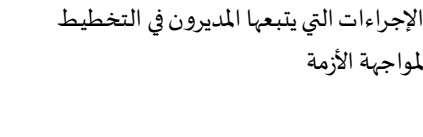 } \\
\hline & &., 510 & $r \Gamma, 0 \leqslant r$ & $\varepsilon 7 r$ & داخل المجموعات & \\
\hline & & $\ldots \ldots \ldots$ & $r \varepsilon, r \vee q$ & $\sum 70$ & المجموع & \\
\hline \multirow[t]{3}{*}{., $7 \varepsilon}$. & \multirow[t]{3}{*}{.,$\leq \leqslant \wedge$} & , ro. &., $0 \ldots$ & $r$ & بين المجموعات & \multirow{3}{*}{ أثناء حدوثهاء الإتي يتبعها المديرون للتعامل مع الأزمة } \\
\hline & &., 009 & $A V, r \mid \varepsilon$ & $\varepsilon 7 \pi$ & داخل المجموعات & \\
\hline & & $\ldots \ldots \ldots$ & $\wedge \gamma, \gamma / 0$ & $\sum 70$ & المجموع & \\
\hline \multirow[t]{3}{*}{., $0_{0}$} & \multirow[t]{3}{*}{., $9 \leqslant \Gamma$} & ., r07 &., 014 & r & بين المجموعات & \multirow[t]{3}{*}{ الدرجة الكلية } \\
\hline & & . & 01,919 & $\sum 7 \pi$ & داخل المجموعات & \\
\hline & & ------ & Or, \&.r & $\sum 70$ & المجموع & \\
\hline
\end{tabular}

تشير النتائج في الجدول أعلاه إلى عدم وجود فروق ذات دلالة إحصائية في درجة ممارسة مدراء المدارس لمهارة إدارة الأزمات من وجهة نظر إلمات

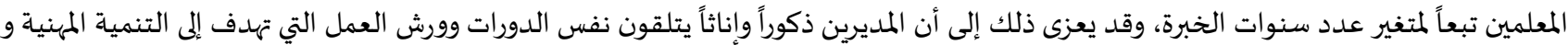

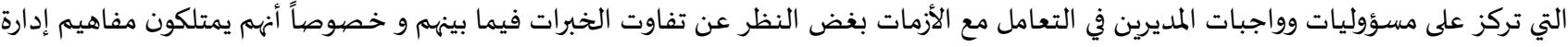

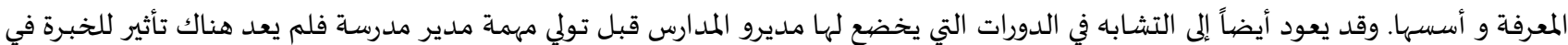

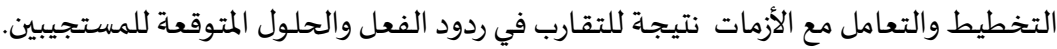

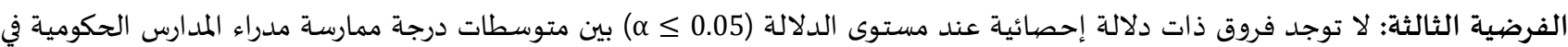

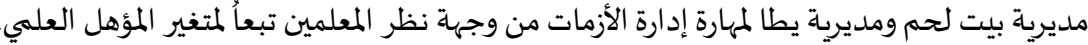

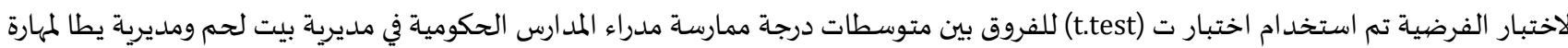

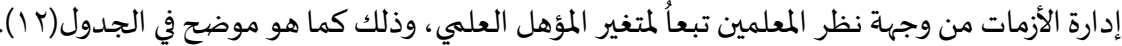

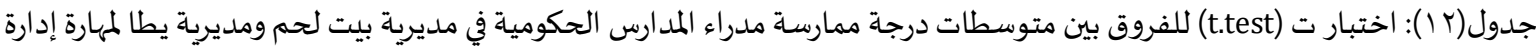

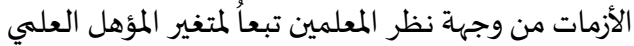

\begin{tabular}{|c|c|c|c|c|c|c|}
\hline الدلالة الإحصائية & قيمة ت المحسوبة & درجات الحرية & الانحراف المعياري & المستوسط المسي & المؤهل العلمي & المجالات \\
\hline \multirow[t]{2}{*}{$\cdot, \varepsilon \vee 9$} & \multirow[t]{2}{*}{$\cdot, \times 1}$. & \multirow[t]{2}{*}{$\varepsilon 7 \pi$} &., . 0 & $\varepsilon, 10$ & بكالوريوس فما دون & \multirow{2}{*}{ الأزمة الإجراءات التي يتبعها المديرون لتجنب حدوث } \\
\hline & & &., $0 \leqslant$ & $\varepsilon, . \wedge$ & أعلى من بكالوريوس & \\
\hline \multirow[t]{2}{*}{. I. } & \multirow[t]{2}{*}{ 1,.rr } & \multirow[t]{2}{*}{$\varepsilon 7 r$} & $\cdot, \varepsilon r$ & $r, v \varepsilon$ & بكالوريوس فما دون & \multirow{2}{*}{$\begin{aligned} \text { الإجراءات التي يتبعها المديرون في التخطيط الأزمة } & \text { المواجية }\end{aligned}$} \\
\hline & & &., 71 & r, Tr & أعلى من بكالوريوس & \\
\hline \multirow[t]{2}{*}{$\cdot, 901$} & \multirow[t]{2}{*}{., . or } & \multirow[t]{2}{*}{$\varepsilon 7 \pi$} & $\cdot, \times 1$ & r,ir & بكالوريوس فما دون & \multirow{2}{*}{ 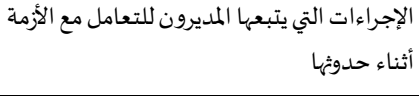 } \\
\hline & & & $\cdot, \mathrm{VV}$ & $r, 11$ & أعلى من بكالوريوس & \\
\hline \multirow[t]{2}{*}{., $0 \wedge T$} & \multirow[t]{2}{*}{., 091} & \multirow[t]{2}{*}{$\varepsilon 7 r$} & , or & r,דV & بكالوريوس فما دون & \multirow[t]{2}{*}{ الدرجة الكلية } \\
\hline & & & . $7 \varepsilon$ & $r, \imath$. & أعلى من بكالوريوس & \\
\hline
\end{tabular}

تشير النتائج في الجدول أعلاه إلى عدم وجود فروق ذات دلالة إحصائية في درجة ممارسة مدراء المدارس لمهارة إدارة الأزمات من وجهات نظر

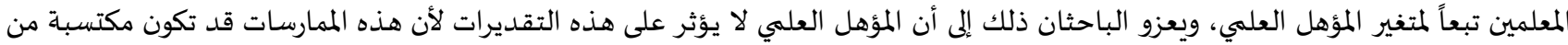

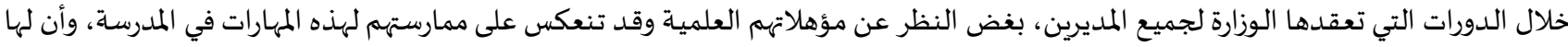

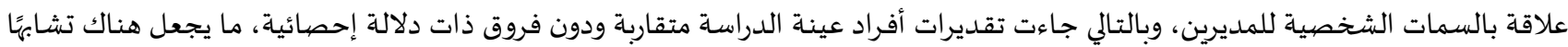
بين وجهات نظر المستجيبين. الفرضية الر ابعة: لا توجد فروق ذات دلالة إحصائية عند مستوى الدلالة (0.05 د م) بين متوسطات درجة ممارسة مدراء المدارس الحكومية في

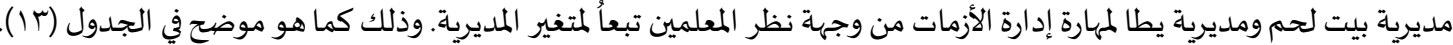


الجدول (س ا): متوسطات درجة ممارسة مدراء المدارس الحكومية في مديرية بيت لحم ومديرية يطا لمهارة إدارة الأزمات من وجهة نظر المعلمين تبعاُ لمتغير المديرية

\begin{tabular}{|c|c|c|c|}
\hline الانحراف المعياري & المتوسط الحسابي & المديرية & المجالات \\
\hline .,Or & $\varepsilon, 1 \varepsilon$ & يطا & \multirow{2}{*}{ الألزمة اءاء التي يتبعها المديرون لتجنب حدوث } \\
\hline.,$r \varepsilon$ & $\varepsilon, 11$ & بيت لحم & \\
\hline.,$£ \varepsilon$ & r,vo & يطا & \multirow{2}{*}{ 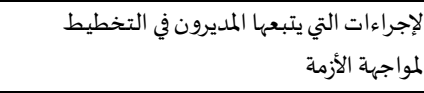 } \\
\hline.,$\leqslant 7$ & $r, \uparrow$. & بيت لحم & \\
\hline.,$\vee \varepsilon$ & $r, .7$ & يطا & \multirow{2}{*}{ أثناء حدوثهاء التي يتبعها المديرون للتعامل مع الأزمة } \\
\hline., $0 \mathrm{~V}$ & $r, \varepsilon 1$ & بيت لحم & \\
\hline., $\mathrm{OV}$ & $r, 70$ & يطا & \multirow[t]{2}{*}{ الدرجة الكلية } \\
\hline 胍. & $r, v 1$ & بيت لحم & \\
\hline
\end{tabular}

جدول (ع ا): نتائج اختبارتحليل التباين الأحادي (one way analysis of variance) درجة ممارسة مدراء المدارس الحكومية في مديرية بيت لحم ومديرية يطا لمهارة

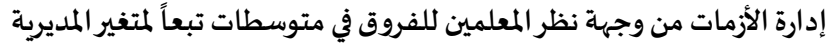

\begin{tabular}{|c|c|c|c|c|c|c|}
\hline الدلالة الإحصائية & قيمة F المحسوبة & متوسط المربعات & مجموع المربعات & 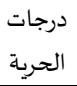 & مصدر التباين & المجالات \\
\hline \multirow{3}{*}{., rTA } & \multirow{3}{*}{$1,10 \mathrm{~V}$} & ., Y०9 & $\cdot, \mathrm{V} \vee \wedge$ & $r$ & بين المجموعات & \multirow{3}{*}{ الأزمة الإجراءات التي يتبعها المديرون لتجنب حدوث } \\
\hline & & . TYE & $r \varepsilon, V r u$ & $\varepsilon 7 r$ & داخل المجموعات & \\
\hline & & ----- & $r_{0}, 1 \varepsilon$ & $\varepsilon 70$ & المجموع & \\
\hline \multirow[t]{3}{*}{$*_{.,}, . \leqslant 7$} & \multirow{3}{*}{ T,VYA } &., $0 \mathrm{VT}$ & 1,119 & $r$ & بين المجموعات & \multirow{3}{*}{ 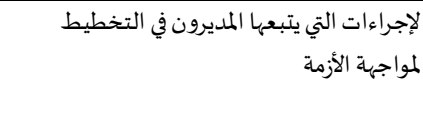 } \\
\hline & &.,$Y$. & rT,07. & $\varepsilon 7 T$ & داخل المجموعات & \\
\hline & & ----- & $r \varepsilon, r \vee q$ & $\varepsilon 70$ & المجموع & \\
\hline \multirow[t]{3}{*}{$* ., \ldots$} & \multirow[t]{3}{*}{$V, Y Y$} & $r, 0 \wedge 7$ & $1 ., 209$ & $r$ & بين المجموعات & \multirow{3}{*}{ أثناء حدوثهاء الإتات يتبعها المديرون للتعامل مع الأزمة } \\
\hline & & $\cdot, \sum 97$ & $V 7,907$ & $\sum 7 T$ & داخل المجموعات & \\
\hline & & --- & $1 V, V 10$ & $\varepsilon 70$ & المجموع & \\
\hline \multirow[t]{3}{*}{., 1 To } & \multirow[t]{3}{*}{$r, v \cdot r$} & 1,049 & $\varepsilon, \varepsilon 19$ & $r$ & بين المجموعات & \multirow[t]{3}{*}{ الدرجة الكلية } \\
\hline & & . ז. & $\varepsilon \wedge, \cdot \wedge \varepsilon$ & $\varepsilon 7 T$ & داخل المجموعات & \\
\hline & & ------- & or,o.r & $\leqslant 70$ & المجموع & \\
\hline
\end{tabular}

تشير النتائج في الجدول أعلاه إلى عدم وجود فروق ذات دلالة إحصائية في متوسطات استجابات المعلمين في المجال الأول المتعلق بالإجراءات التي

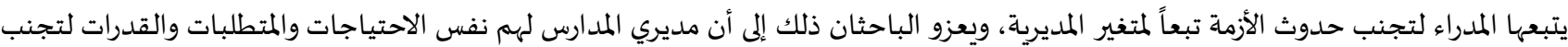
حدوث الأزمة بغض النظر عن المديرية التي يتبعون لها وذلك نتيجة لخضوعهم لنفس الدورات التدريبية والقرارات والنشرات الإدارية التي تصدرها وزارة التربية والتعليم وتعممهها على جميع المديريات. وأشارت النتائج إلى وجود فروق ذات دلالة إحصائية في المجال الثاني المتعلق بالإجراءات التي يتبعها المدراء في التخطيط لمواجهة الأزمة وكانت

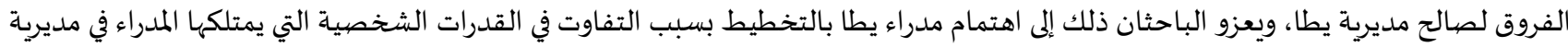
يطا عن زملأههم في مديرية بيت لحمى مديرسه. وأشـارت النتائج إلى وجود فروق مدئ ذات بـات دلالة إحصائية في المجال الثالث المتعلق بالإجراءات التي يتبعها المدراء للتعامل مع الأزمة أثناء حدوثها وكانت

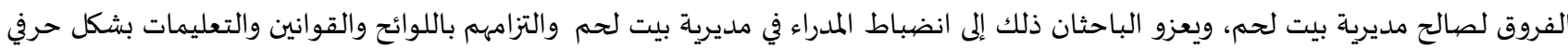
بصورة ميزتهم عن زملاكهم في مديرية يطا.

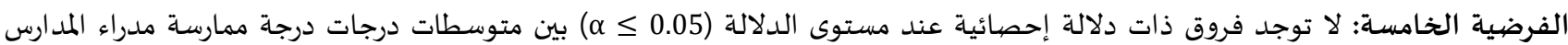

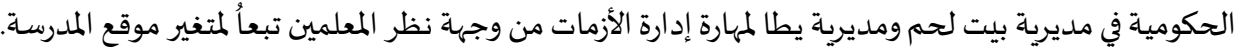

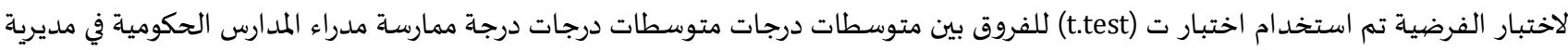

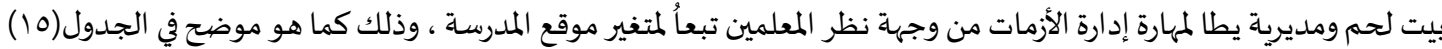


جدول (10) : نتائج اختبارت (t.test) للفروق بين متوسطات درجات درجة ممارسة مدراء المدارس الحكومية في مديرية بيت لحم ومديرية يطا لمهارة إدارة الأزمات من وجهة نظر المعلمين تبعاً لمتغير موقع المدرسة مدان

\begin{tabular}{|c|c|c|c|c|c|}
\hline الدالة الإحصائية & قيمة ت المحسوبة & درجات الحرية & الانحراف المعياري & المستوسطي & موقع المدرسة \\
\hline \multirow[t]{2}{*}{., $9 \wedge \mathrm{r}$} & \multirow[t]{2}{*}{.,$. Y Y-$} & \multirow[t]{2}{*}{ rqA } & . Tr & $\varepsilon, \Gamma \wedge$ & قرية \\
\hline & & & ., ह1 & $\varepsilon, r_{q}$ & مدينة \\
\hline
\end{tabular}

تشير النتائج في الجدول أعلاه إلى عدم وجود فروق ذات دلالة إحصائية في درجة ممارسة مدراء المدارس لمهارة إدارة الأزمات من وجهة نظر

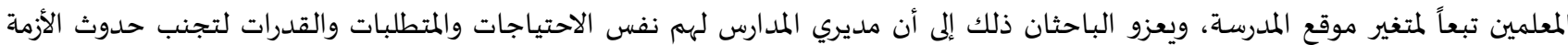
والتخطيط لمواجهتها والتعامل معها أثناء حدوثها بغض النظر عن المديرية التي يتبعون لها وذلك نتيجة لخضوعهم لنفس التهات الدورات التدريبية والقرارات

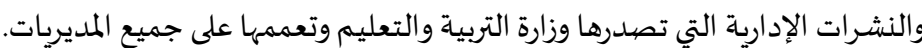
وفي ضوء نتائج الدراسـة يوصي الباحثان بما يلي:

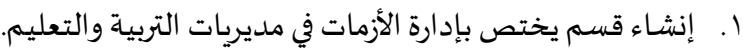
r. تزويد مدراء المدارس بملفات تتضمن بعض الأزمات المدرسية التي حدثت من قبل وكيفية التعامل الصحيح معها.

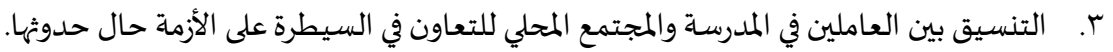

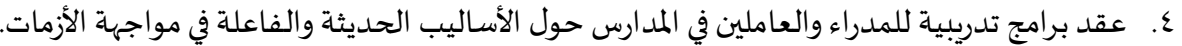
0. تشكيل فريق لإدارة الأزمات في كل مدرسة برئاسـة المدير وعضوية المرشد الاجتماعي وبعض المعلمين.

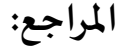

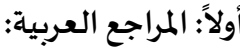

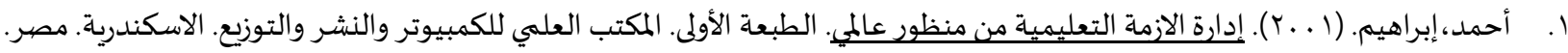

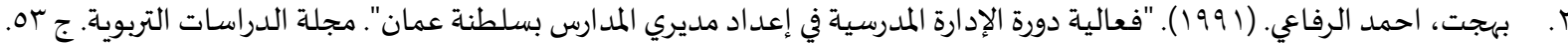

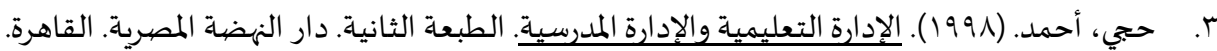
ع. الحمد ان، جاسم، والدلماني، زيد. (Y (ب). إدارة الأزمات المدرسية. دار المسيلة للنشر والتوزيع. الكويت.

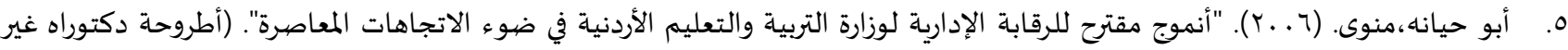
منشورة). جامعة عمان العربية للدارسات العليا. عمان. الأردن.

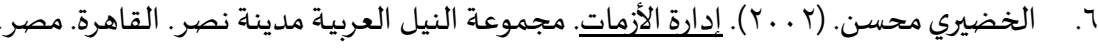

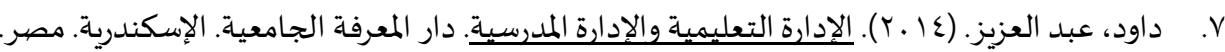

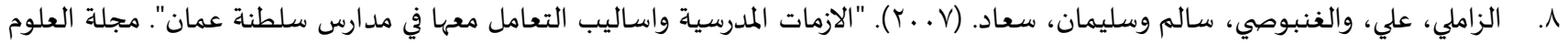

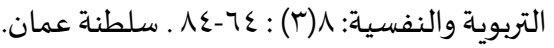
صراص، مها كامل. (10 • ب). "واقع إدارة الأزمات في المدارس الخاصة في محافظتي بيت لحم ورام الله والبيرة من وجهة نظر مديريها ومعلميها". رسالة ماجستير غير منشورة. جامعة القدس. فلسطين.

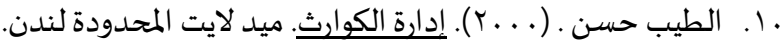

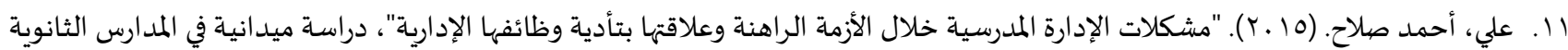
العامة في مدينة دمشق، رسالة ماجستير غير منشورة. دمشق. سوريا.

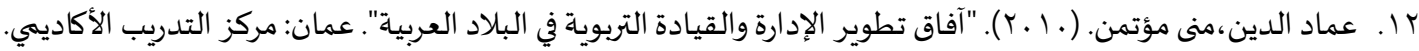

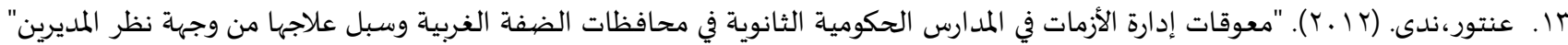
رسالة ماجستير غير منشورة. جامعة النجاح. نابلس. فلسطين.

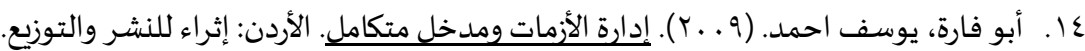

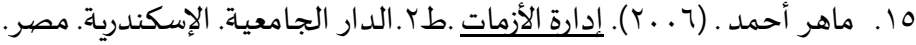

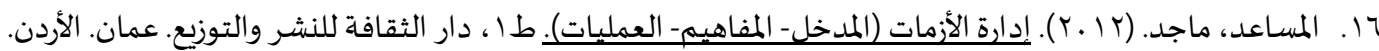




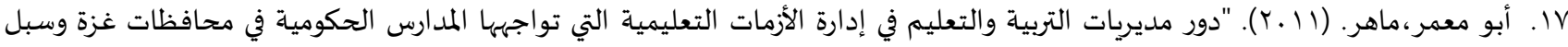
تطويره". رسالة ماجستير غير منشورة. جامعة الأزهر. غزة. فلسطين.

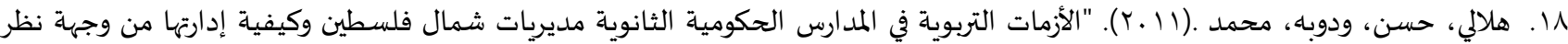

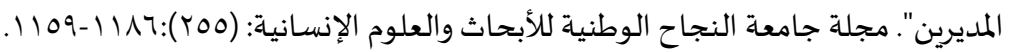

9 ا. الهنائي، منيرة. (ץ ..ب). "معوقات الادارة المدرسية لدى مديري المدارس الثانوية بالداخلية". رسالة ماجستير غير منشورة. جامعة السلطان قابوس. عمان. r. . . وزارة التخطيط والتعاون الدولي. (199V).الاصد ار الاول ، السلطة الوطنية الفلسطينية. ثانياً: المراجع الأجنبية:

[1] Liming, R, (2010). "stress sources and coping strategies of secondary public-school principals", unpublished doctoral, university of Denver, intemet, no, AAC991358.

[2] Mitagang, l. (2002). "The Making of The Five Lessons in Leadership Training". the Wallace foundation, knowledge center, New York 
المجلة الدولية للدراسـات التربوية والنفسية

International Journal of Educational \& Psychological Studies (EPS)

Journal Homepage: https://www.refaad.com/views/EPSR/Home.aspx

www.refaad.com

ISSN: 2520-4149 (Online) 2520-4130 (Print)

\title{
The degree to which school principals in the Bethlehem and Yatta Education Directorates practice the skill of crisis management from the teachers' points of view
}

\author{
Jamal Bheis \\ Associate Professor of Educational Administration and Planning, Al-Quds Open University, Palestine \\ jbheis@qou.edu \\ Ismail Mohammed Alafandi \\ Lecturer in Administration and Educational Planning, Al-Quds Open University, Palestine \\ iafandi@qou.edu
}

Abstract: The study aimed to identify the degree of government school principals' practice of crisis management skill, and the impact of variables: (gender, educational qualification, number of years of experience, directorate, and school location). The sample consisted of (300) teachers working in Bethlehem and Yatta chosen by simple random method, and the researchers used a questionnaire consisting of (30) paragraphs. The results indicated that government school principals' practice of the skill of crisis management was significantly. The study showed that the field related to the procedures followed by the principals came in the first order, then the field related to the procedures followed by the principals in planning to face the crisis, while the third field was related to the procedures followed by the principals in dealing with the crisis during its occurrence. No statistically significant differences according to the variables (educational qualification, years of experience, and the location of the school). while it showed statistically significant differences according to the gender variable. No statistically significant differences according to the directorate variable in the first field. However, statistically significant differences according to the variable of the directorate in the second field.

Keywords: crisis management skill; teachers' viewpoints; public-school.

\section{References:}

[1] 'ly, Ahmd Slah. (2015). "Mshklat Aledarh Almdrsyh Khlal Alazmh Alrahnh W'laqtha Btadyh Wza'fha Aledaryh", Drash Mydanyh Fy Almdars Althanwyh Al'amh Fy Mdynh Dmshq, Rsalt Majstyr Ghyr Mnshwrh. Dmshq. Swrya.

[2] 'mad Aldyn,Mna M'tmn. (2010). "Afaq Ttwyr Aledarh Walqyadh Altrbwyh Fy Alblad Al'rbyh". 'man: Mrkz Altdryb Alakadymy.

[3] 'ntwr,Nda. (2012). "M'wqat Edart Alazmat Fy Almdars Alhkwmyh Althanwyh Fy Mhafzat Aldfh Alghrbyh Wsbl 'lajha Mn Wjht Nzr Almdyryn" Rsalt Majstyr Ghyr Mnshwrh. Jam't Alnjah. Nabls. Flstyn.

[4] Ahmd, Ebrahym. (2001). Edart Alazmh Alt'lymyh Mn Mnzwr 'almy. Altb'h Alawla. Almktb Al'lmy Llkmbywtr Walnshr Waltwzy'. Alaskndryh. Msr.

[5] Bhjt, Ahmd Alrfa'y. (1991). "F'alyt Dwrt Aledarh Almdrsyh Fy 'dad Mdyry Almdars Bsltnt 'man". Mjlt Aldrasat Altrbwyh. J 53.

[6] Dawd, 'bd Al'zyz. (2014). Aledarh Alt'lymyh Waledarh Almdrsyh. Dar Alm'rfh Aljam'yh. Aleskndryh. Msr.

[7] Abw Farh, Ywsf Ahmd. (2009). Edart Alazmat Wmdkhl Mtkaml. Alardn: Ethra' Llnshr Waltwzy'.

[8] Hjy, Ahmd. (1998). Aledarh Alt'lymyh Waledarh Almdrsyh. Altb'h Althanyh. Dar Alnhdh Almsryh. Alqahrh.

[9] Hlaly, Hsn, Wdwbh, Mhmd. (2011). "Alazmat Altrbwyh Fy Almdars Alhkwmyh Althanwyh Mdyryat Shmal Flstyn Wkyfyt Edartha Mn Wjhh Nzr Almdyryn". Mjlt Jam't Alnjah Alwtnyh Llabhath Wal'lwm Alensanyh: (255):1186-1159.

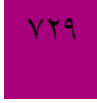

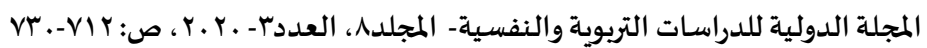


[10] Alhmdan, Jasm, Waldlmany, Zyd. (2013). Edart Alazmat Almdrsyh. Dar Almsylh Llnshr Waltwzy'. Alkwyt.

[11] Alhna'ey, Mnyrh. (2002). "M'wqat Aladarh Almdrsyh Lda Mdyry Almdars Althanwyh Baldakhlyh". Rsalt Majstyr Ghyr Mnshwrh. Jam't Alsitan Qabws. 'man.

[12] Abw Hyanh, Mnwa. (2006). "Anmwj Mqtrh Llrqabh Aledaryh Lwzart Altrbyh Walt'lym Alardnyh Fy Dw' Alatjahat Alm'asrh". (Atrwht Dktwrah Ghyr Mnshwrh). Jam't 'man Al'rbyh Lldarsat Al'lya. 'man. Alardn.

[13] Alkhdyry Mhsn. (2002). Edart Alazmat. Mjmw't Alnyl Al'rbyh Mdynt Nsr. Alqahrh. Msr.

[14] Mahr Ahmd. (2006). Edarh Alazmat. T2. Aldar Aljam'yh. Aleskndryh. Msr.

[15] Abw M'mr,Mahr. (2011). "Dwr Mdyryat Altrbyh Walt'elym Fy Edart Alazmat Alt'elymyh Alty Twajhha Almdars Alhkwmyh Fy Mhafzat Ghzh Wsbl Ttwyrh". Rsalt Majstyr Ghyr Mnshwrh. Jam't Alazhr. Ghzh. Flstyn.

[16] Almsa'd, Majd. (2012). Edart Alazmat (Almdkhl- Almfahym- Al'mlyat). T1, Dar Althqafh Llnshr Waltwzy'. 'man. Alardn.

[17] Sras, Mha Kaml. (2015). "Waq' Edart Alazmat Fy Almdars Alkhash Fy Mhafzty Byt Lhm Wram Allh Walbyrh Mn Wjht Nzr Mdyryha Wm'lmyha". Rsalt Majstyr Ghyr Mnshwrh. Jam't Alqds. Flstyn.

[18] Altyb Hsn. (2000). Edart Alkwarth. Myd Layt Almhdwdh Lndn.

[19] Wzart Altkhtyt Walt'awn Aldwly. (1997). Alasdar Alawl, Alslth Alwtnyh Alflstynyh.

[20] Alzamly, 'ly, Walghnbwsy, Salm Wslyman, S'ad. (2007). "Alazmat Almdrsyh Wasalyb Alt'aml M'ha Fy Mdars Sltnt 'man". Mjlt Al'lwm Altrbwyh Walnfsyh: 8(3): 64-84. Sltnt 'man. 